\title{
Phase II Final Report:
}

\section{Air Transportable Expeditionary Crane}

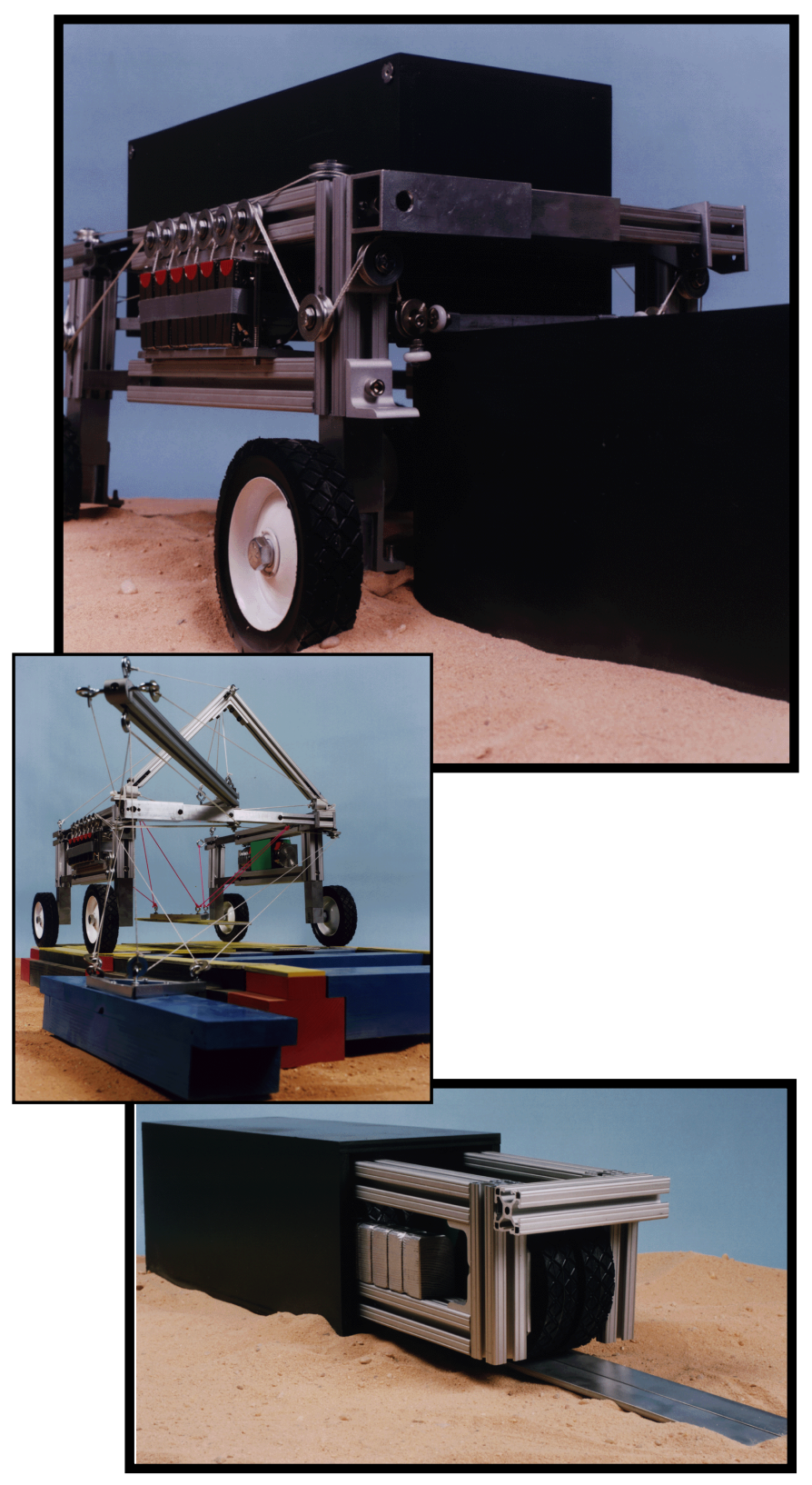

Prepared For:

Lynn Torres

Marine Corps Program Manager

Naval Facilities Engineering Service Center

CO,CDNSWC

Code 102

Bethesda, Maryland 20084-5000

Tasked By:

Marine Corps Systems Command (MARCORSYSCOM)

Amphibious Warfare Technology Directorate (Code AW)

Submitted By:

\section{Dr. James S. Albus}

Intelligent Systems Division

National Institute of Standards and Technology Gaithersburg, Maryland 20899 


\section{TABLE OF CONTENTS}

ADMINISTRATIVE INFORMATION 1

CONTRACT SPECIFICATIONS

ATEC DESIGN CONFIGURATIONS ..................................

Container Mobilizer …............................................... 5

Concept and Capabilities $\quad$..........................................................5

Packaging/Deployment Sequence …………………………...

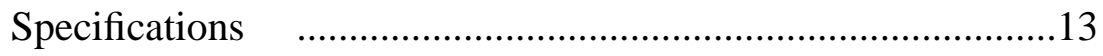

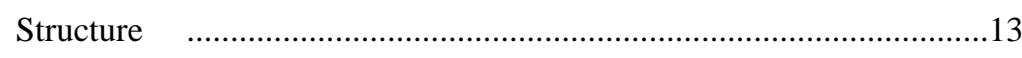

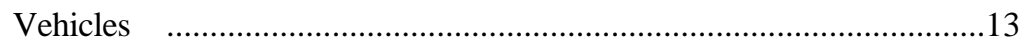

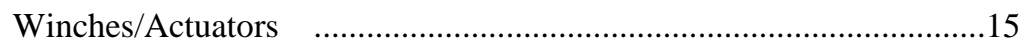

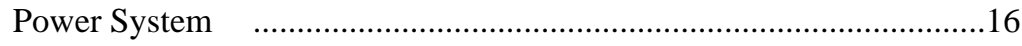

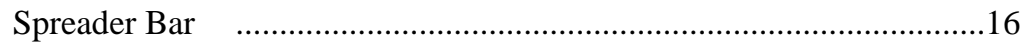

Cantilevered Material Handler .................................... 19

Concept and Capabilities ........................................................19

Packaging/Deployment Sequence ...........................................22

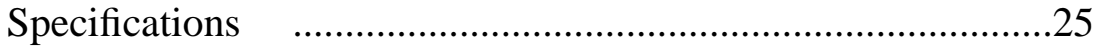

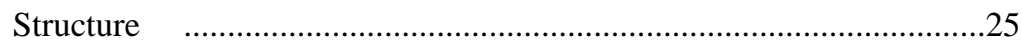

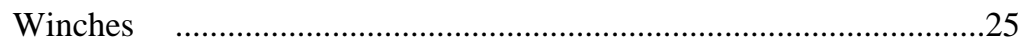

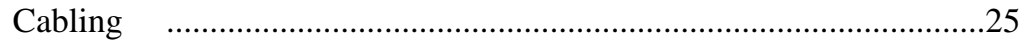

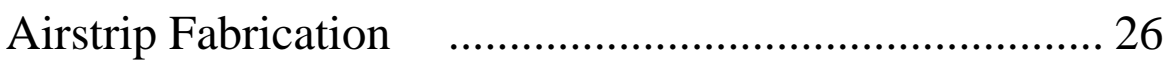

Airstrip Assembly Assumptions $\quad$..............................................28

Assembly Sequence and Timing $\quad$................................................29

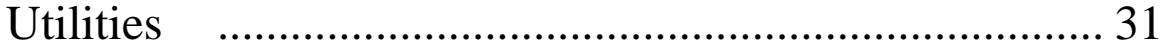

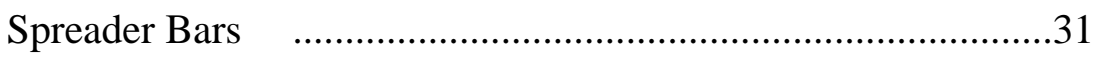




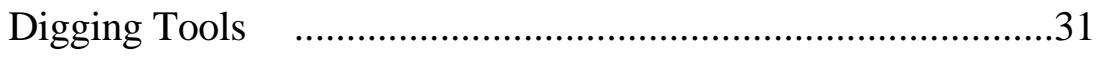

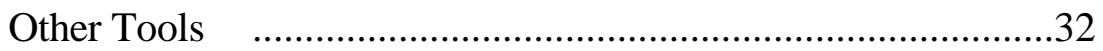

Model Photos ...............................................................34

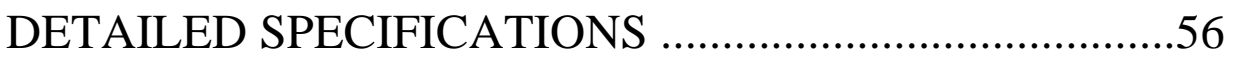

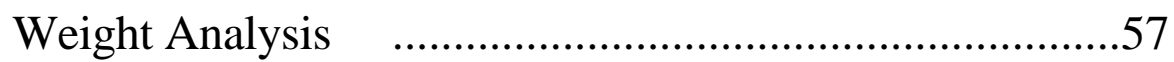

Cost and Fabrication Time ...........................................57

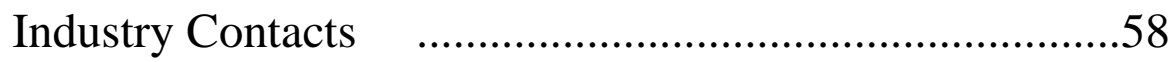

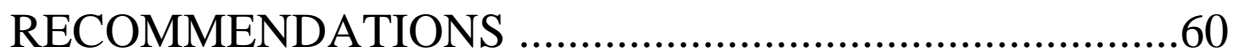

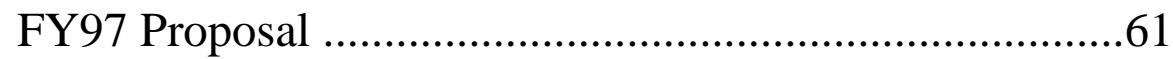

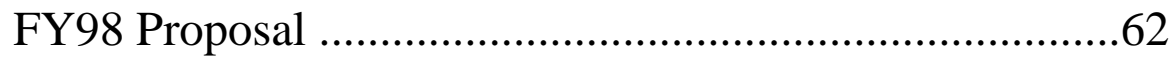

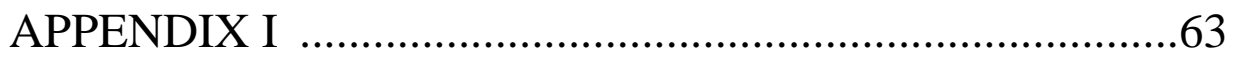

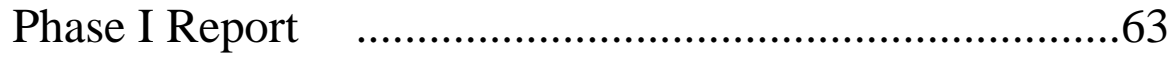

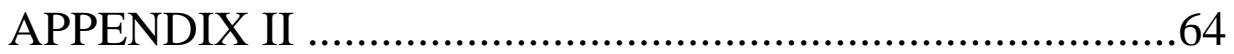




\section{ADMINISTRATIVE INFORMATION}

\section{Project Title}

Air Transportable Expeditionary Crane Project

[References to this report should be made to MIPR \#M9545095MPR5

prepared on March 1, 1995]

\section{Start / End Dates}

March 1, 1995 / September 30, 1995

\section{Resource Budget}

\$40K for FY95

\section{Responsible Person / Organization}

\section{Shujie Chang, P.E.}

Marine Corps Program Manager

Naval Facilities Engineering Service Center

CO,CDNSWC - Code 102

Bethesda, Maryland 20084-5000

\section{Cooperating Organization}

Marine Corps Systems Command

(MARCORSYSCOM)

Amphibious Warfare Technology Directorate

(Code AW) 


\section{Performing Organization}

National Institute of Standards and Technology

Intelligent Systems Division

Building 220 Office B124

Gaithersburg, MD 20899

\section{Point of Contact}

Mr. Roger Bostelman

Phone: 301-975-3426

Email: roger.bostelman@ @ist.gov

\section{Principal Investigators}

Dr. James Albus

Mr. Roger Bostelman

Mr. Adam Jacoff
Phone: 301-975-3418

Email: james.albus@nist.gov

Phone: 301-975-3426

Email: roger.bostelman@nist.gov

Phone: 301-975-4235

Email: adam.jacoff@nist.gov

\section{Associate Investigators}

Ms. Kimberly Anderson

Mr. Charles Giauque

Mr. Brian Weiss

\section{Key Words}

Cranes, ISO Container Handling, Heavy Cargo Transport, All Terrain Vehicles, Airstrip Construction, Drilling, Digging, Robotics, Sensory Interactive Machines 


\section{CONTRACT SPECIFICATIONS}

The concept of an Air-Transportable Expeditionary Crane (ATEC) must satisfy a few important mission requirements. That is, it must be transported via helicopter to an unimproved expeditionary site. It must be deployed quickly with a minimum of personnel. It must be able to acquire and mobilize $23 \mathrm{t}^{*}$ (25 ton) ISO containers across rough terrain. It should be able to stack containers two high. And lastly, it should perform a number of tasks associated with constructing a landing strip for cargo aircraft in an expeditionary environment. In order to accomplish these rigorous goals, a successful ATEC design must balance structural ruggedness against weight, overall size against transportability and cargo stability against dexterity.

The ATEC - Container Mobilizer must be extremely lightweight compared to conventional container handlers. The structure must be designed to operate without using heavy counterweights as ballast. It must also be flexible enough to be packaged efficiently in an $2.5 \mathrm{~m} \times 2.5 \mathrm{~m} \times 6 \mathrm{~m}(8 \mathrm{ft}$ x $8 \mathrm{ft}$ x $20 \mathrm{ft}$ ) ISO container for quick and easy deployment in the field. Yet the total airlifted package, crane and container together, cannot weigh more than $14.5 \mathrm{t}$ (16 tons). For the ATEC - Container Mobilizer to satisfy all these constraints, an innovative crane has been developed based on existing technologies but with eye toward future technological improvements.

Therefore, the FY95 research objective was to design and evaluate the technical feasibility of a heavy lift crane with the following design criteria:

- Lightweight enough to be helicopter transportable.

- Compact enough to be packaged in standard $2.5 \mathrm{~m}$ x $2.5 \mathrm{~m}$ x $6 \mathrm{~m}(8 \mathrm{ft}$ x $8 \mathrm{ft}$ x $20 \mathrm{ft}$ ) ISO containers.

- Capable of rapid deployment in the field.

- Lift capacity of $23 \mathrm{t}$ (25 ton) with quick acquisition of ISO container size loads

- Capable of rapidly constructing an airfield from pre-assembled, modular components.

- Capable of performing a wide variety of other material handling tasks such as acquiring, moving and placing munitions, fuel/water tanks and palletized cargo.

- Capable of carrying out a variety of other combat engineering tasks such as digging trenches, drilling holes for footings, berming and 
clearing trees.

The overall long term goal of this project is to develop and field-demonstrate a full scale prototype crane.

$* 1 \mathrm{t}($ metric ton $)=1000 \mathrm{~kg}$ 


\section{ATEC DESIGN CONFIGURATIONS}

\section{Container Mobilizer}

\section{Concept and Capabilities}

Our conceptual design for the ATEC - Container Mobilizer is based on existing mobile gantry cranes (see Figure 1). Although our target capacity is $23 \mathrm{t}$ ( $25 \mathrm{ton}$ ), we have chosen a structure more closely sized to a 45 $t$ (50 ton) crane to compensate for the rugged requirements of rough terrain. However, our main structural members, hollow box beams, would be fabricated from high strength aluminium instead of steel to lower the overall weight while maintaining structural integrity. In addition, our ATEC's structural members can telescope within other hollow members to allow the complete structure to retract itself, while staying basically intact, to fit into an ISO container for transport.

\section{FIGURE 1.}

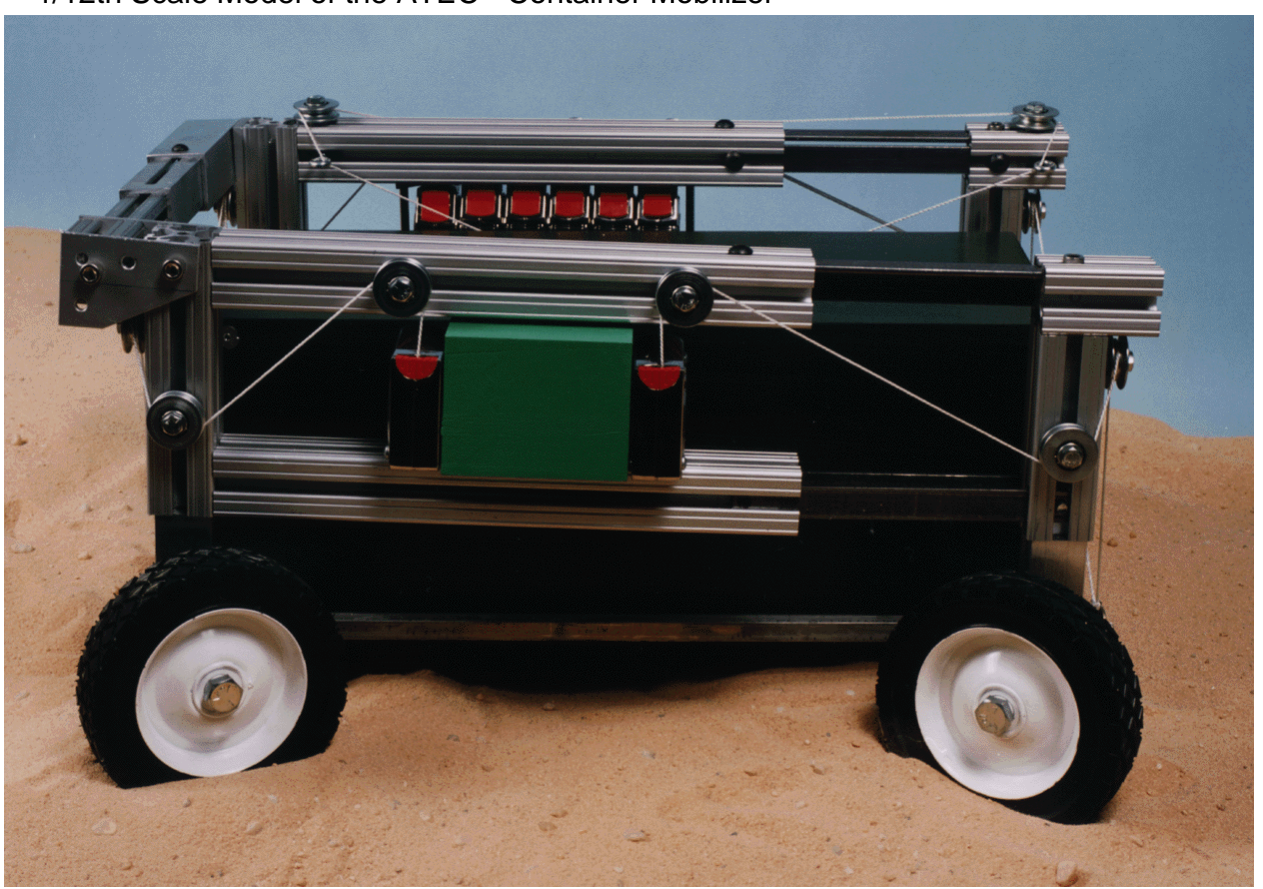


The Container Mobilizer is powered by a single diesel engine mounted on one of the crane's side frames. Power is dispersed throughout the crane via hydraulic lines and hoses safely located within the hollow structural members. Hydraulic fluid and diesel fuel are also housed in tanks located within the lower structural members of the crane. The hydraulic lines power all four drive wheels, the steering motors, eight heavy duty winches for container stability and six lighter duty winches for Stewart Platform (Stewart, "A Platform with Six Degrees of Freedom," The Institution of Mechanical Engineers, vol. 180, Part I, No. 15, pp. 371-386, Proceeding 1965-1966.) control to perform additional tasks. Auxillary hydraulic power ports will be located in the front and rear of the crane to provide power for tools such as spreader bars, drills, excavating equipment and saws.

In order to improve maneuverability while reducing the Container Mobi-

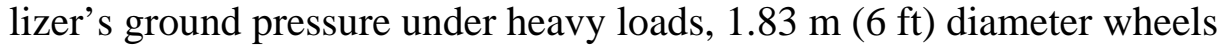
are mounted outside the frame on vertical pillars allowing $120^{\circ}$ of rotation about each leg. This innovation will greatly improve the Container Handlers steering capability while approaching and mobilizing ISO containers. Several steering modes are available to the operator: 4 wheel steering on a $6 \mathrm{~m}(20 \mathrm{ft})$ radius, "spin-on-a-dime" steering, and side-toside (crab) steering as well.

Operator controls can be plugged into the front or rear of the ATEC Container Mobilizer to provide the best vantage point. The portable operator panel will permit teleoperation of loads and control of the hydrostatic drive, similar to standard mobile gantry cranes.

The ATEC - Container Mobilizer is designed to straddle a standard $2.5 \mathrm{~m}$ x $2.5 \mathrm{~m}$ × $6 \mathrm{~m}$ ( $8 \mathrm{ft}$ × $8 \mathrm{ft}$ x $20 \mathrm{ft}$ ) ISO container weighing up to $23 \mathrm{t}$ ( 25 ton). It can pick or place a container on the ground, a flat-bed truck, or on top of another ISO container. The ATEC can pick up the container from the top or bottom ISO locks using a rectangular spreader bar. Once acquired, the ATEC - Container Handler can maneuver the container with 6 Degrees-of-Freedom (DoF) control and stability.

The container handler's dexterity is such that it can stably place the container on two pedestal locks located at the base of two of the crane's side legs. Once resting on these pedestals, the ISO container is then engaged via it's upper ISO locks by two twist pins protruding from the top of the same legs. The attached cables (through the spreader bar) completely constrain the container and provide redundancy during mobility. The ATEC can then mobilize the ISO container with more than $0.9 \mathrm{~m} \mathrm{(3 \textrm {ft } )}$ ground clearance while traveling at speeds of up to $16 \mathrm{~km} / \mathrm{h}(10 \mathrm{mph})$ Higher speeds are possible with a larger engine and drive system gear 
changes.

By attaching the spreader bar to the container bottom, stacking is achieved by allowing the container to hoist up through the crane frame to the height as shown in Figure 2.

\section{FIGURE 2.}

ATEC - Container Mobilizer showing Stacking Capability

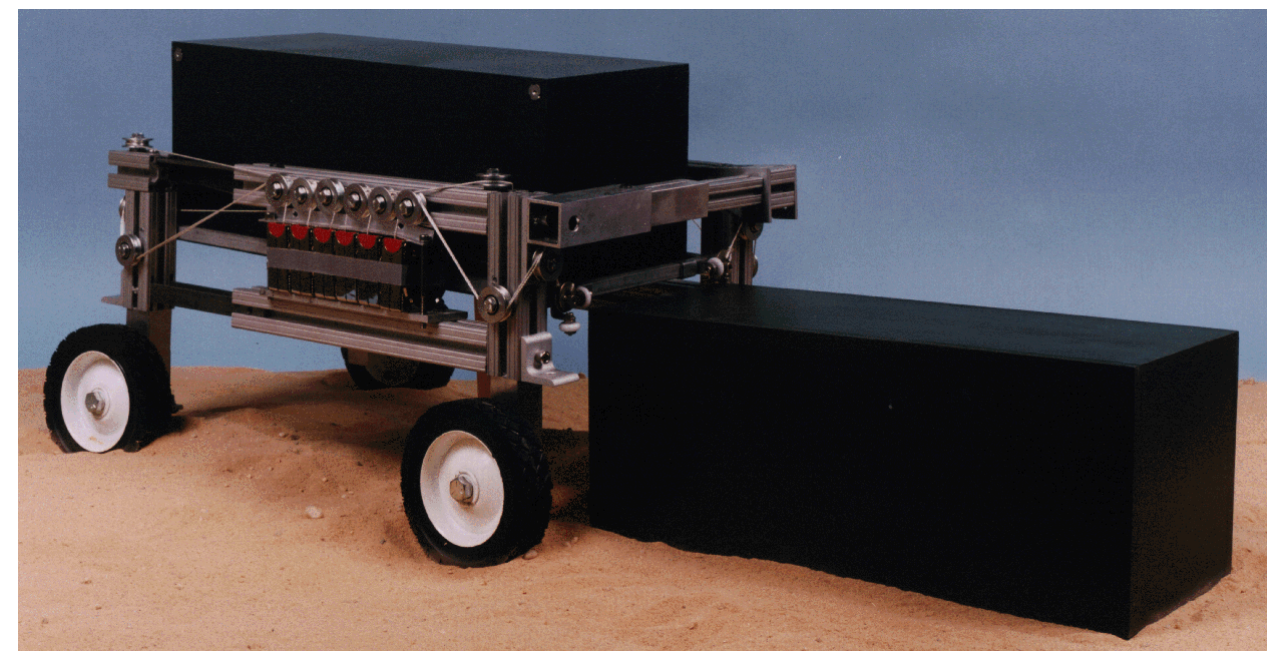

The ATEC - Container Handler will weigh approximately $10.6 \mathrm{t}$ (11.5 tons) including additional components for reconfiguration into an ATEC Cantilevered Material Handler. By packaging the ATEC into a MILVAN ISO Container weighing $2.2 \mathrm{t}$ (2.4 tons), the total shipping weight of the ATEC is $12.7 \mathrm{t}$ (14 tons). That is light enough to be transported by helicopter.

Other ATEC capabilities include the attachment of grippers or other material handling equipment to the spreader bars for doing: equipment/ vehicle maintenance, flexible fixturing, and material handling of breakbulk (miscellaneous small cargo). By attaching saws to the spreader bars, the user can adapt the ATEC to cut and remove trees and debris.

Additionally, the ATEC - Container Mobilizer can perform functions such as berming and excavation with a high speed digging tool, similar to a trench digger, attached to a triangular spreader bar. By running the digging arm along the ground using teleoperative control of the platform/ tool, the operator can carve earth in the exact location desired. Pushing or scraping earth is possible, by mobilizing a heavy container for ballast with a bull-dozer style blade attached to the spreader bar. The blade could then be controlled via teleoperation. 


\section{Packaging/Deployment Sequence}

The ATEC delivery will be via air transport while housed within a standard ISO $2.5 \mathrm{~m} \times 2.5 \mathrm{~m} \times 6 \mathrm{~m} 8 \mathrm{ft} \times 8 \mathrm{ft} \times 20 \mathrm{ft}$ ) ISO container (see Figure 3). Packaging will require unfastening and pivoting the wheels within the retracted gantry.

The engine and winches are on slides that are manually pulled-out and are fastened during deployment.

The container handling spreader bar breaks down, folds, and mounts to an upper frame location for stow while allowing the winches to remain attached and ready for quick deployment. Two triangular spreader bars can be fabricated from the container handling spreader bar.

Components necessary to deploy the ATEC - Cantilevered Material Handler are also broken-down and fit within the packaged gantry and wheels. Items for this ATEC configuration are the: Boom, A-frame Vertical stay, winches, and support cabling.

The following is a procedure that describes the deployment steps shown in Figures 4 and 5. The bracketed numbers show the number of people times the approximate amount of time for each step.

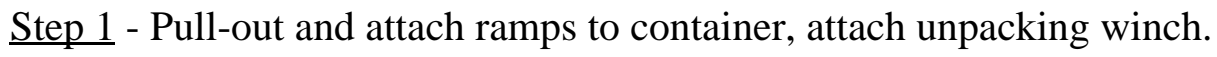
[2 people for $5 \mathrm{~min}$ ]

$\underline{\text { Step } 2}$ - Winch crane out of container and onto ramps. [1 person for 5 $\min ]$

$\underline{\text { Step } 3}$ - Safety check/engine start to warm hydraulic system, fill lines. [1 person for $2 \mathrm{~min}]$

$\underline{\text { Step } 4}$ - Attach 4 jacks to frame ( 2 on each side). [8 people for $2 \mathrm{~min}$ ]

$\underline{\text { Step } 5}$ - Crank jacks to unload wheels, remove wheels from stow, jack to full height, attach wheels, remove jacks. [8 people for $10 \mathrm{~min}$ ]

$\underline{\text { Step } 6}$ - Slide out and secure winches and engine. [4 people for $5 \mathrm{~min}$ ]

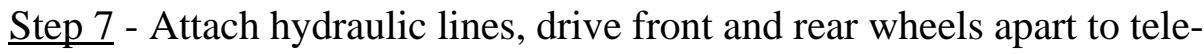
scope.[3 people for $2 \mathrm{~min}$ ]

$\underline{\text { Step } 8}$ - Rotate wheels $90^{\circ}$ to "crab" position and drive apart to telescope to Container Mobilizer or Airstrip Construction Crane width. [1 person for $4 \mathrm{~min}$ ]

$\underline{\text { Step } 9}$ - Rotate wheels back, attach spreader bar or work platform and tool(s).[4 persons for $5 \mathrm{~min}$ ]

Minimum total elapsed deployment time $=40 \mathrm{~min} *$. 
*Note: The approximate step timing is simply a measure estimated by the researchers. No basis is given for these time estimates. Therefore, a conservative deployment time estimate of less than one hour is feasible. With fewer people, the time estimate will increase. 
FIGURE 3.
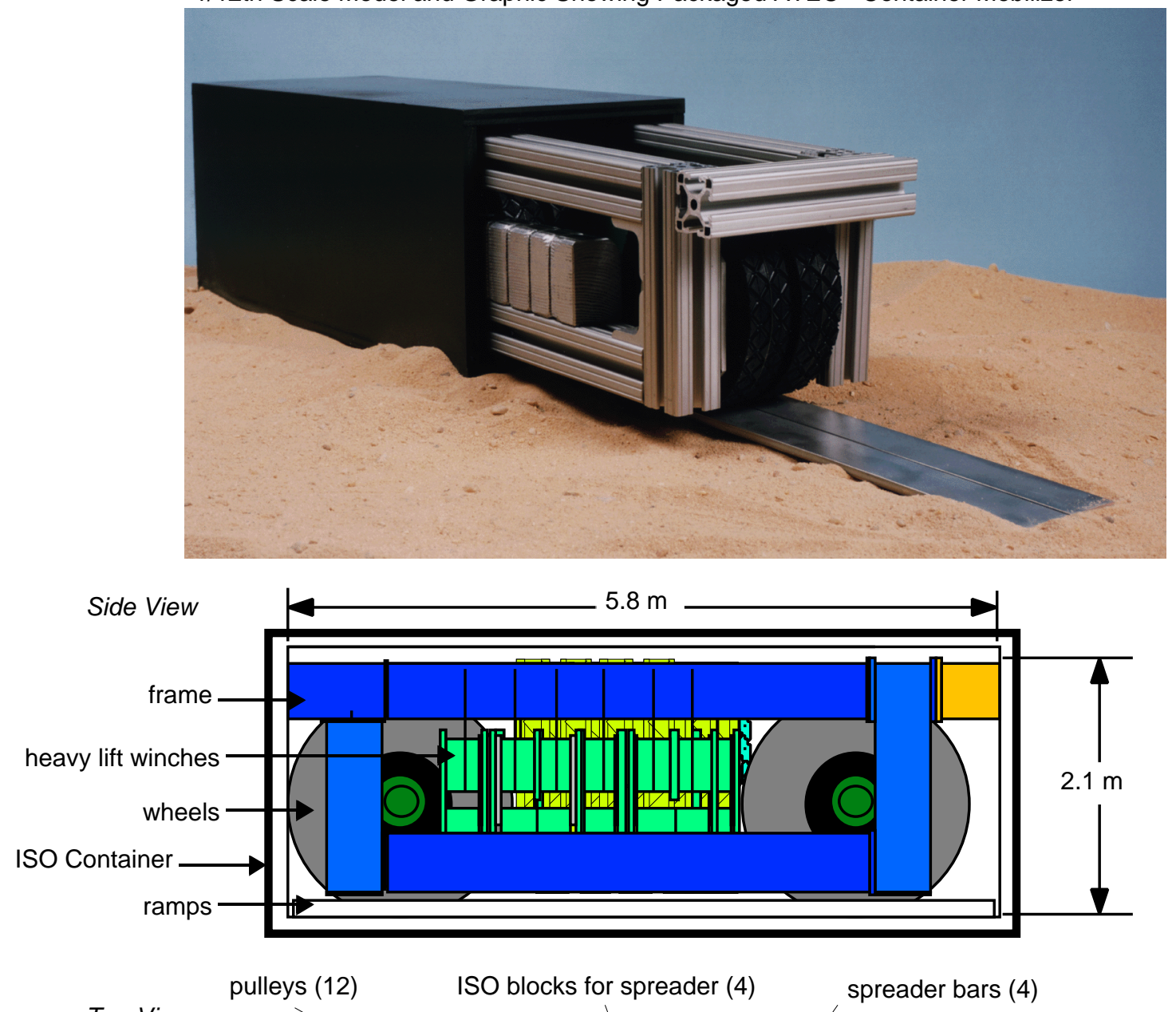

Top View

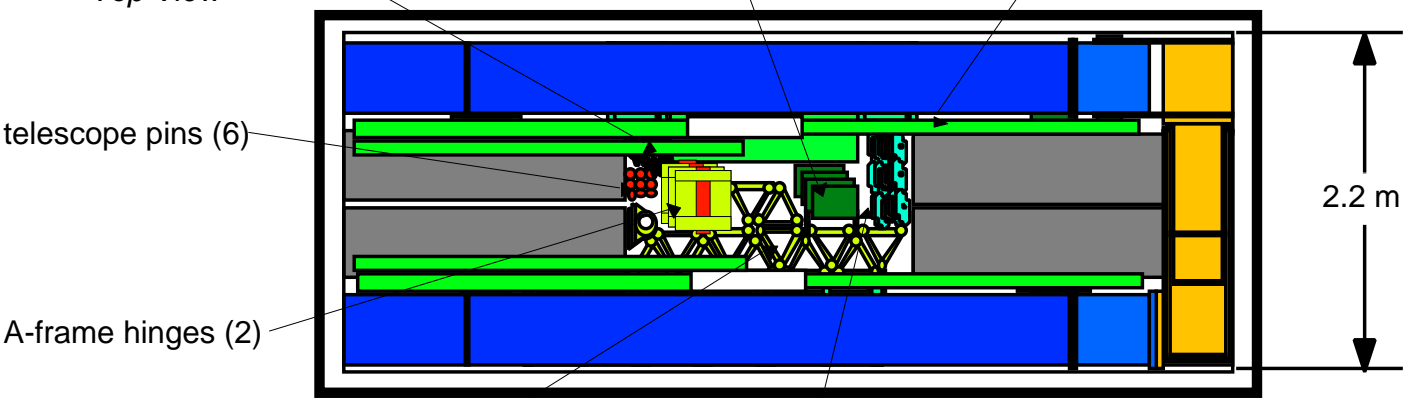


FIGURE 4.

Step 1

Step 2

Step 4

Step 3

Step 5
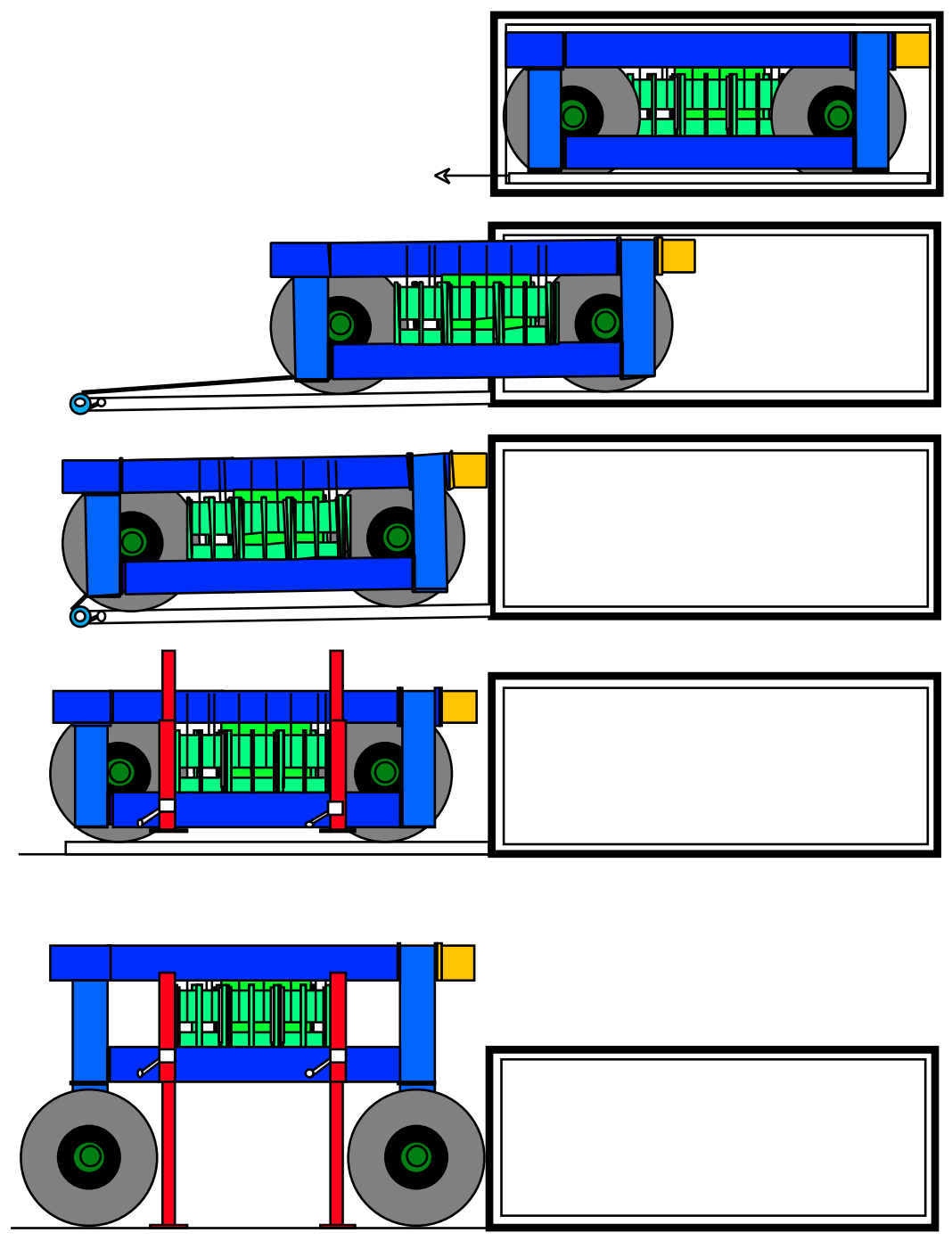

Step 5 
FIGURE 5.

Deployment Sequence for the ATEC - Container Mobilizer (Steps 6 - 9)

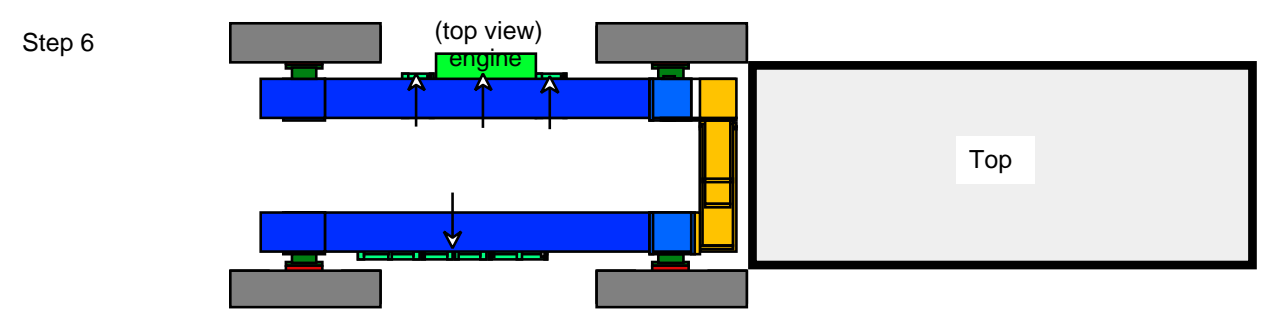

Step7

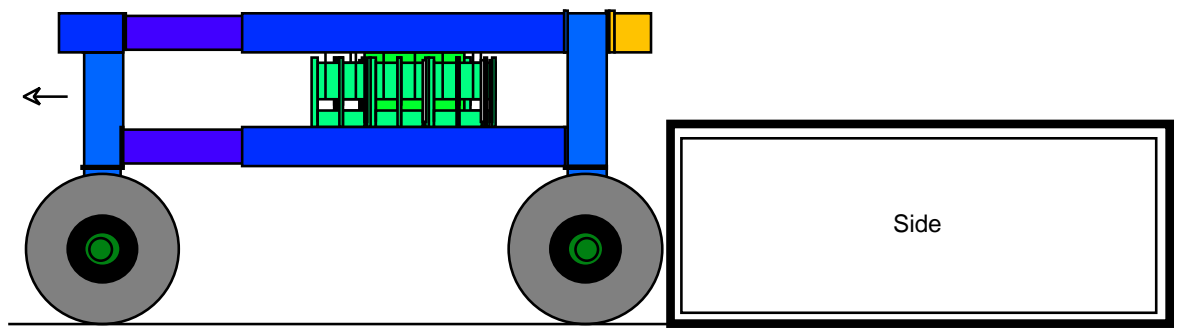

Step 8
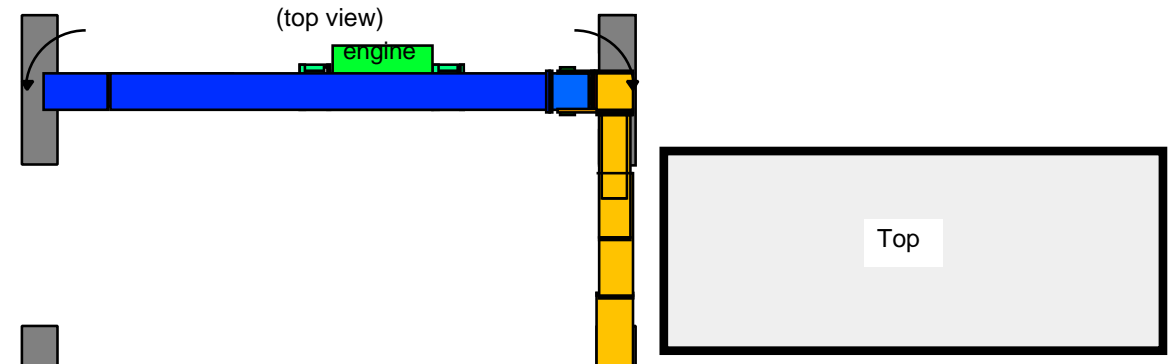

Step 9

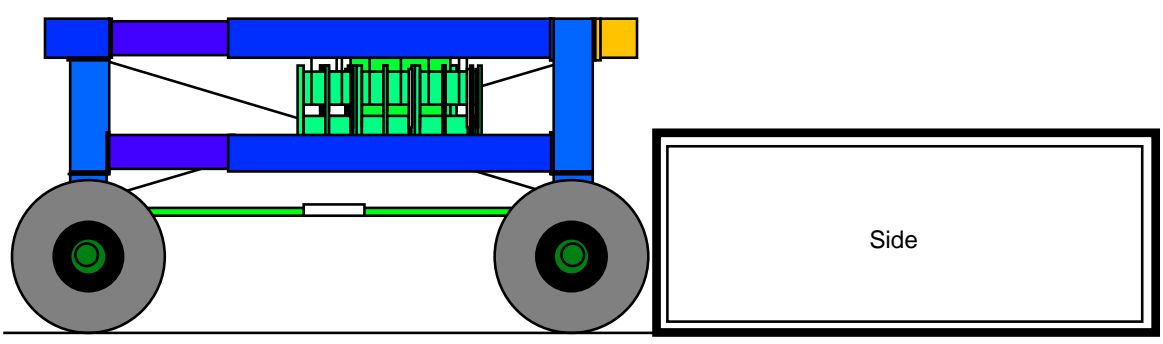




\section{Specifications}

\section{Structure}

\section{FIGURE 6.}

Vehicles
The structure of the ATEC - Container Mobilizer is similar to a standard mobile gantry crane. Two rectangular structural frames made from $46 \mathrm{~cm}$ (18 in) aluminum box beams provide the major support. Members composing the frames are passively (as opposed to actively) telescoped in length to package the large frames within a standard ISO container measuring $2.5 \mathrm{~m} \times 2.5 \mathrm{~m} \times 6 \mathrm{~m}(8 \mathrm{ft} \times 8 \mathrm{ft} \times 20 \mathrm{ft})$ externally.

A passively-telescoped (no added power required to telescope), widthexpansion member connects the two structural frames. The width member reduces from an $46 \mathrm{~cm}$ (18 in) box beam down to a $30 \mathrm{~cm}$ (12 in) box beam using five members. The ATEC - Container Mobilizer extends 4 of the 5 members, or reduces from an 18 in beam to only $36 \mathrm{~cm}$ (14 in) beam. The $36 \mathrm{~cm}$ (14 in) beam also houses the $30 \mathrm{~cm}$ (12 in) beam. For full width extension to $6 \mathrm{~m}$ (19'10”) structural width, the $30 \mathrm{~cm}$ (12 in) box beam is then extended.

The left frame connection is fixed with a series of bolts fastening two flanges. The right side is connected via a trunnion joint allowing the right frame to pivot, with respect to the joint, in the vertical plane. The joint

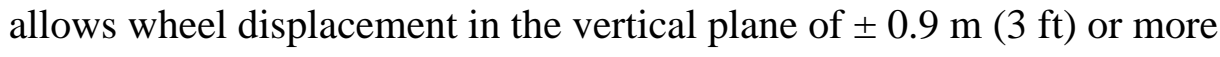
allowing motion over rough terrain. This simple and effective joint creates little or no maintenance over the life of the crane. This joint is shown in Figure 6.

Cut-away view of Right ATEC Side Showing Fluid Storage Tanks

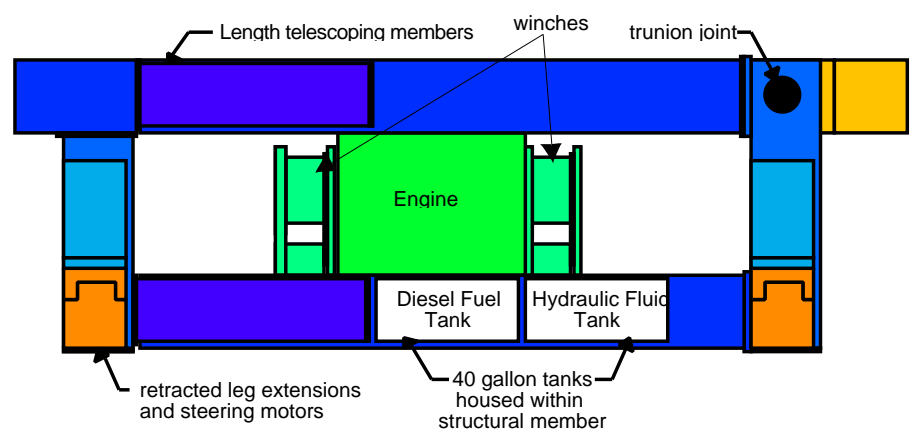

The wheels are $1.8 \mathrm{~m}(6 \mathrm{ft})$ diameter $\mathrm{x} 0.5 \mathrm{~m}(1.5 \mathrm{ft})$ wide and are mounted on the outside of the frame. The design shown in Figure 7 shows a portion of the leg fastened to a steering motor. The wheel then attaches to the steering motor housed within a heavy duty joint via a 
wheel connector with the hydraulical motor attached to the wheel. To attach the wheel to the leg during deployment (see Figure 8), the steering motor and leg extension telescopes from the frame and the wheel can then be attached for use.

FIGURE 7.

ATEC Vehicle Design

A-A' View

Side View
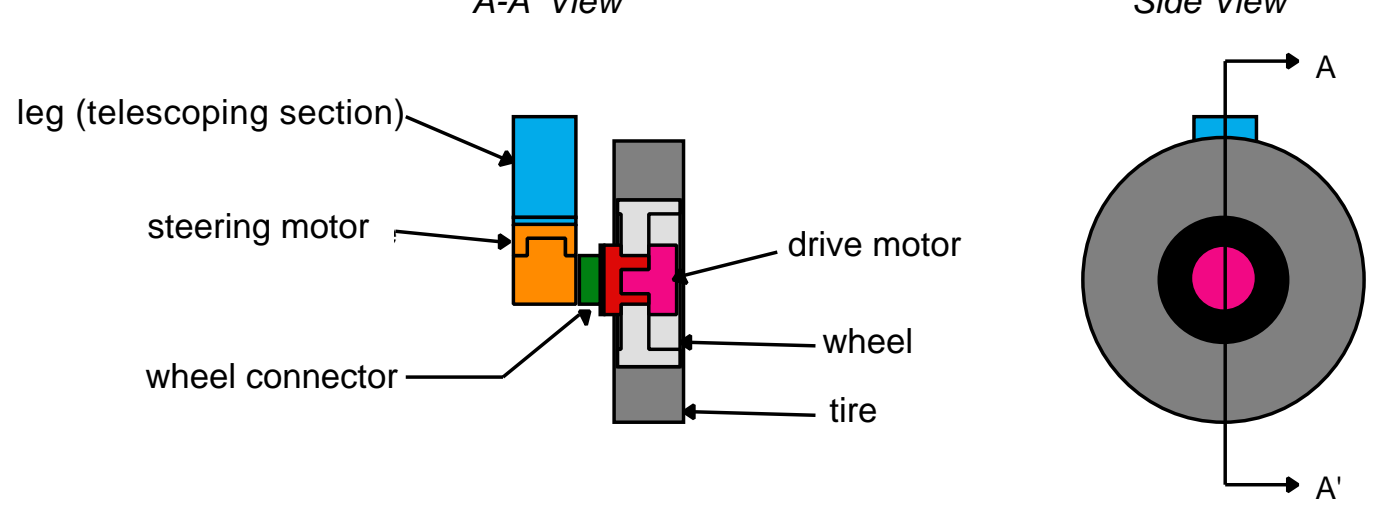

FIGURE 8.

Vehicle Attachment to the ATEC Leg

Leg Telescope and Wheel Attachmen
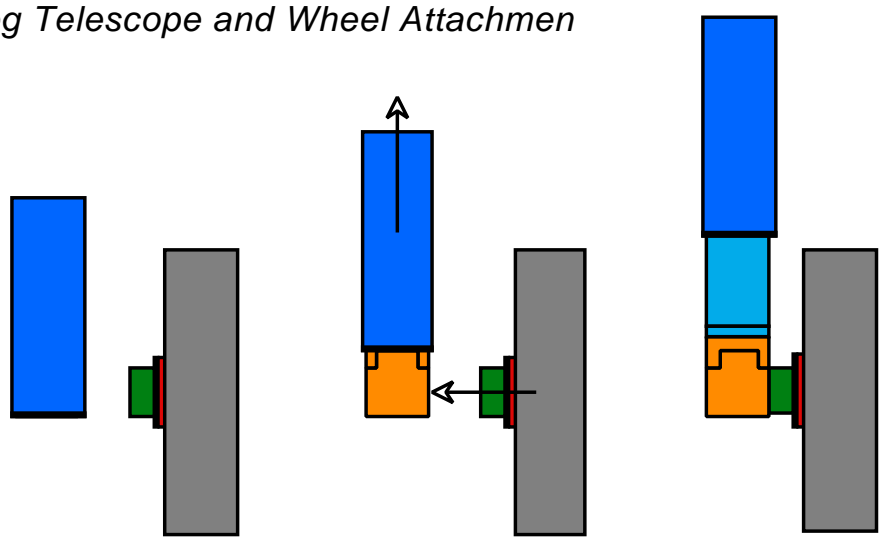

The wheel assembly, including the tires, drive (gear) motor, steering motors, wheels, and wheel connections, weighs approximately $1814 \mathrm{~kg}$ $(4000 \mathrm{lb})$. The ATEC ground loading is approximately $289 \mathrm{kPa}$ (42 psi) with a $23 \mathrm{t}$ ( 25 ton) load evenly distributed across all four wheels. This 
Winches/Actuators compares to the LACH (Lightweight Amphibious Container Handler) with approximately $483 \mathrm{kPa}$ (70 psi) or the RTCH (Rough Terrain Container Handler) with more than $689 \mathrm{kPa}$ (100 psi).

Since there are four independently controlled wheels, multiple steering modes exist. They are as follows: 4 wheel steering on a minimum $6 \mathrm{~m}$ (20 $\mathrm{ft}$ ) radius, "spin-on-a-dime" steering, and side-to-side (crab) steering, as well as combinations of each.

Eight winches are used to control the suspended load (eg. spreader bars, ISO containers, tools, and equipment) in a RoboCrane ${ }^{\circledR}$ configuration. Figure 9 shows the cable configuration for the container handling spreader bar. The cables allow six DOF load control, whether using the container handling or triangular spreader bars. The triangular spreader bar cable configuration is similar to the standard Stewart Platform configuration.

FIGURE 9.

Container Handling Spreader Bar Cable Configuration

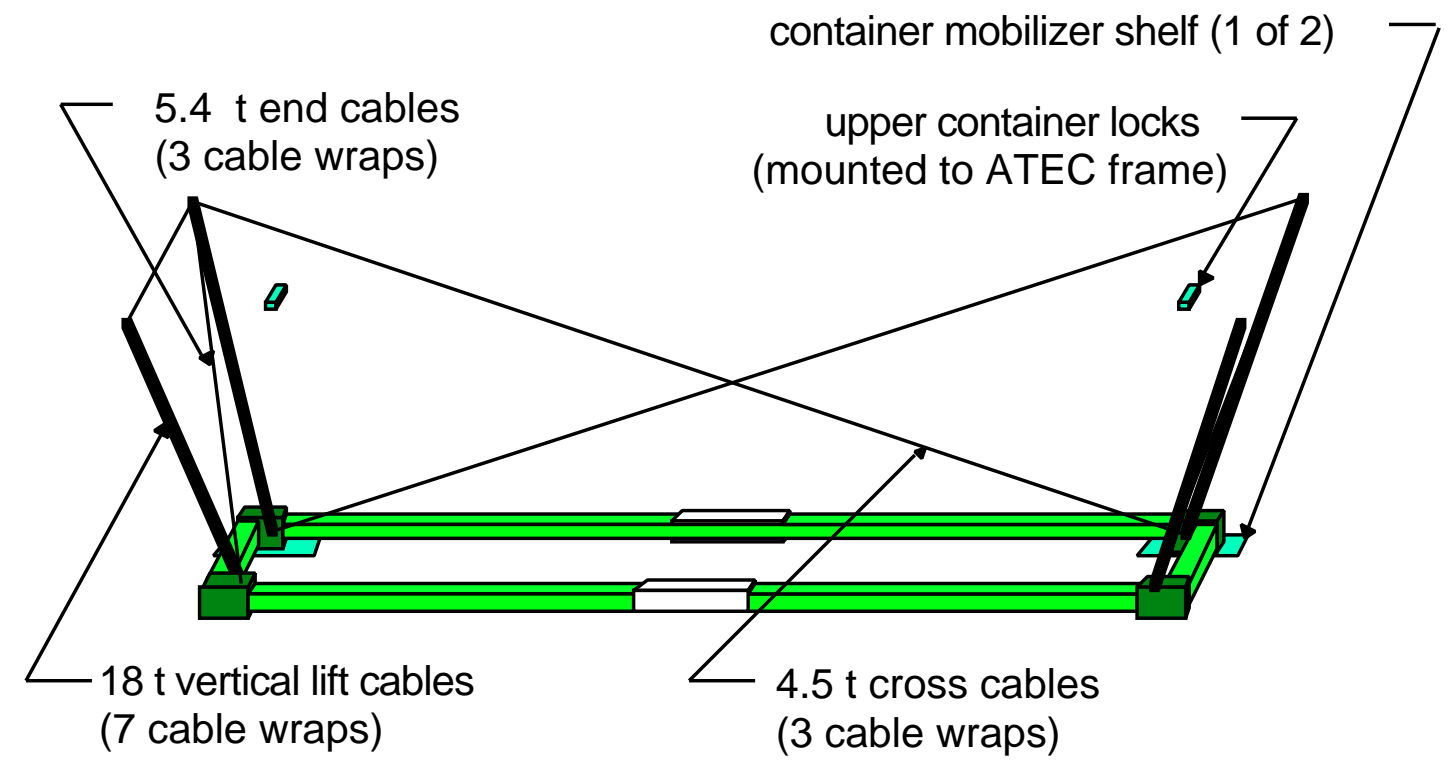

- Upper cable ends contact pulleys.

- Spreader bar rests on shelves and latches to upper container locks. 


\section{Power System}

Spreader Bar
There will be two winch types: 1) A lightweight winch with line speed of $0.46 \mathrm{~m} / \mathrm{min}(90 \mathrm{ft} / \mathrm{min})$ and pull capacity of $907 \mathrm{~kg}(2000 \mathrm{lb})$; 2) A heavy weight winch with line speed of $0.5 \mathrm{~m} / \mathrm{min}(99 \mathrm{ft} / \mathrm{min})$ and pull of 2630 $\mathrm{kg}(5800 \mathrm{lb})$. A aariety of cable wraps will be used to achieve additional speeds and pulls. Sheaves are to be aluminum and easily accessible for changing cables and/or configurations in the field.

ATEC actuators consist of drive and steering gearmotors used for ATEC mobility. These drive systems are hydraulic planetary gearmotors as used in commercial mobile gantry cranes, with similar weight, size, speed, and durability.

The power system is modeled from a standard mobile gantry crane and the single unit system designed during FY94 ATEC project. The ATEC power system consists of a four cylinder diesel engine, gear pump driven off the engine flywheel, hydraulic filter system, hydraulic oil cooler, hydrostatic transmission, and $0.15 \mathrm{~m}^{3}$ (40 gallon) diesel fuel and hydraulic fluid tanks.

A John Deere ** 4039T diesel engine is specified and provides $76 \mathrm{~kW}$ (102 HP) at $2100 \mathrm{r} / \mathrm{min}$ for a standard $45 \mathrm{t}$ (50 ton) mobile gantry crane (see Shuttlelift ${ }^{\mathrm{TM}}$ SL50 Specification Sheet - Appendix II). This same engine or it's equivalent is specified for the ATEC.

Control and actuation is provided to all wheel drives and their steering motors simultaneously. Similarly, all eight winches are controlled and actuated simultaneously. The ATEC could theoretically control all actuators simultaneously but, at a reduction in speed and performance.

Diesel fuel and hydraulic fluid are stored within the engine support structural member as shown in Figure 6. Storage within a structural member provides high puncture resistance and removes the need for additional tank storage volumes.

** The National Institute of Standards and Technology (NIST) does not endorse the products mentioned in this paper. These products are usedfor illustration purposes only and are not mentioned because they are better than another similar product.

The Container Mobilizer spreader bar is packaged with the ATEC ready for deployment and use in container handling. During deployment, the spreader bar is manually assembled quickly and easily. The spreader bar is made from $10 \mathrm{~cm} \times 1.3 \mathrm{~cm}$ (4 inx $1 / 2 \mathrm{in}$ ) wall box beam 6105-T6 aluminum with solid aluminum corners measuring $15 \mathrm{~cm}$ high $\mathrm{x} 30 \mathrm{~cm}$ long x $15 \mathrm{~cm}$ deep (6 in high x 12 in long x 6 in deep) as shown in Figure 10. 
Connection rods made from $13 \mathrm{~cm}(5$ in) aluminum box beam x $1.3 \mathrm{~cm}$ (1/2 in) wall thickness and join the $2.5 \mathrm{~m} \mathrm{(} 8 \mathrm{ft} 4$ in) length members together with locking pins. A similar connection is made at the corners. As shown in cross-section view A-A' in Figure 10, spreader bar connection to an ISO container requires automatic locking mechanisms controlled by a remote operator. This automatic connection acts similar to a solenoid for translating the ISO connector pin into the container during acquisition and rotates via a second solenoid automatically upon translation. This operation could be overridden for manual operation. The hoist ring is suspended from the lift cables and is connected to the ISO pin. Therefore, container lift is achieved at the container and not translated through the spreader bar corners. Therefore, lighter corners are possible. The Container Handling spreader bar weighs approximately $279 \mathrm{~kg}(616$ lb). 
FIGURE 10.

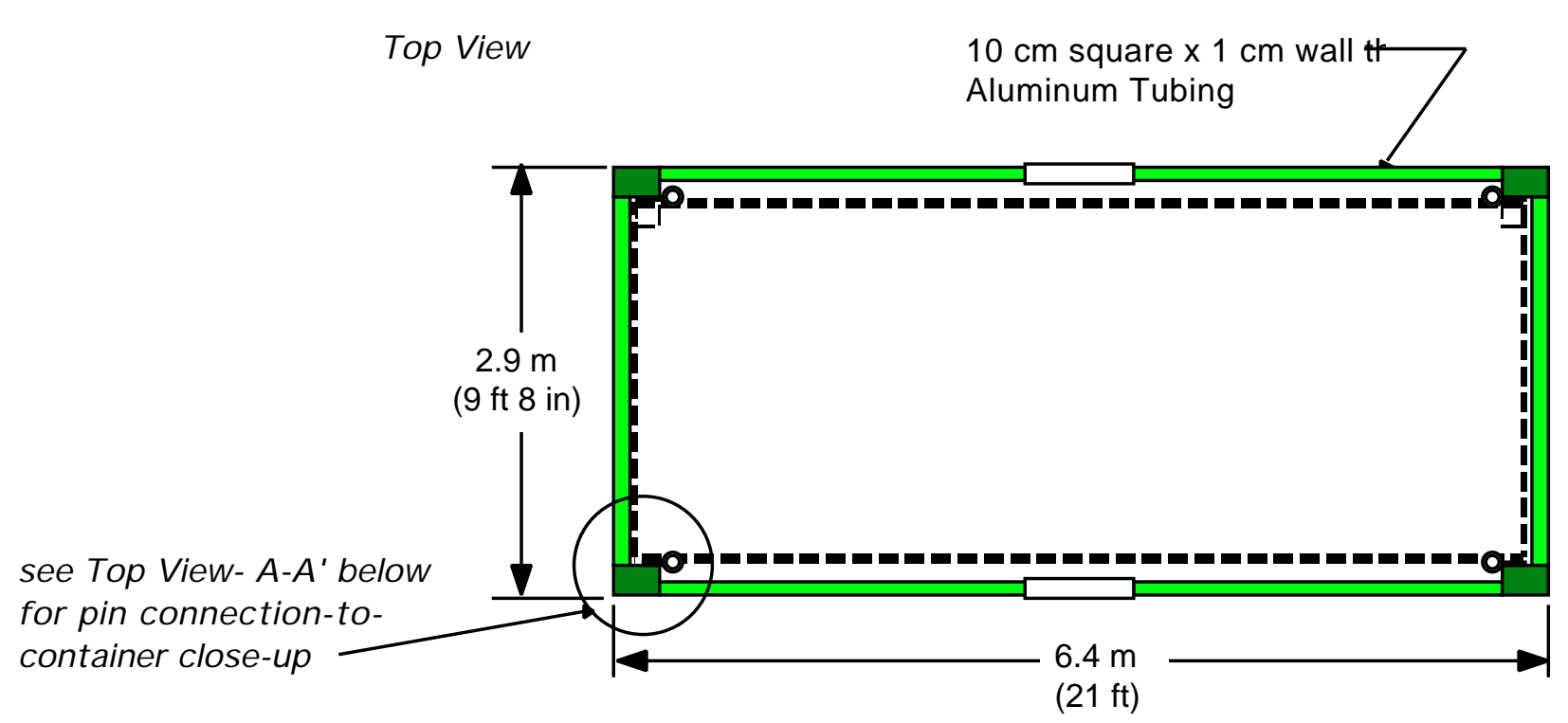

Side View

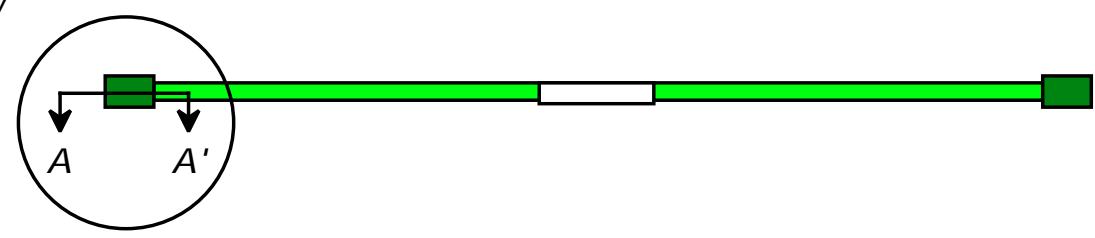

Top View - A-A'
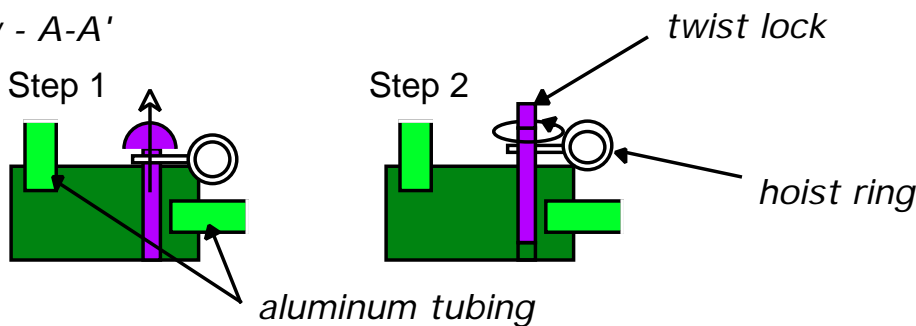

Step 1: push twist lock into container ISO connector

Step 2: rotate twist lock to lock ISO connector to spreader bar 


\section{Cantilevered Material Handler}

\section{Concept and Capabilities}

The ATEC - Cantilevered Material Handler $(\mathrm{CMH})$ is a reconfiguration of the ATEC - Container Mobilizer (See Figure 11). All components of the ATEC - CMH can be packaged and contained within the same shipping container carrying the ATEC - Container Mobilizer. The ATEC Cantilevered Material Handler has two working platforms.

The forward platform is designed to maneuver loads of up to $680 \mathrm{~kg}$ $(1500 \mathrm{lb})$ while at a reach of up to $9.1 \mathrm{~m}(30 \mathrm{ft})$ from the ATEC's main structure. With a load of $680 \mathrm{~kg}$ at $9.1 \mathrm{~m}$, the ATEC-CMH has a safety factor of 5 against tipping. Similarly, $680 \mathrm{~kg}$ supported by the ATEC-

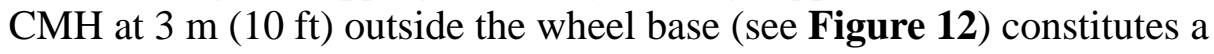
safety factor of 18 against rolling over.

FIGURE 11.

Side View of the ATEC - Cantilevered Material Handler showing Cantilever System

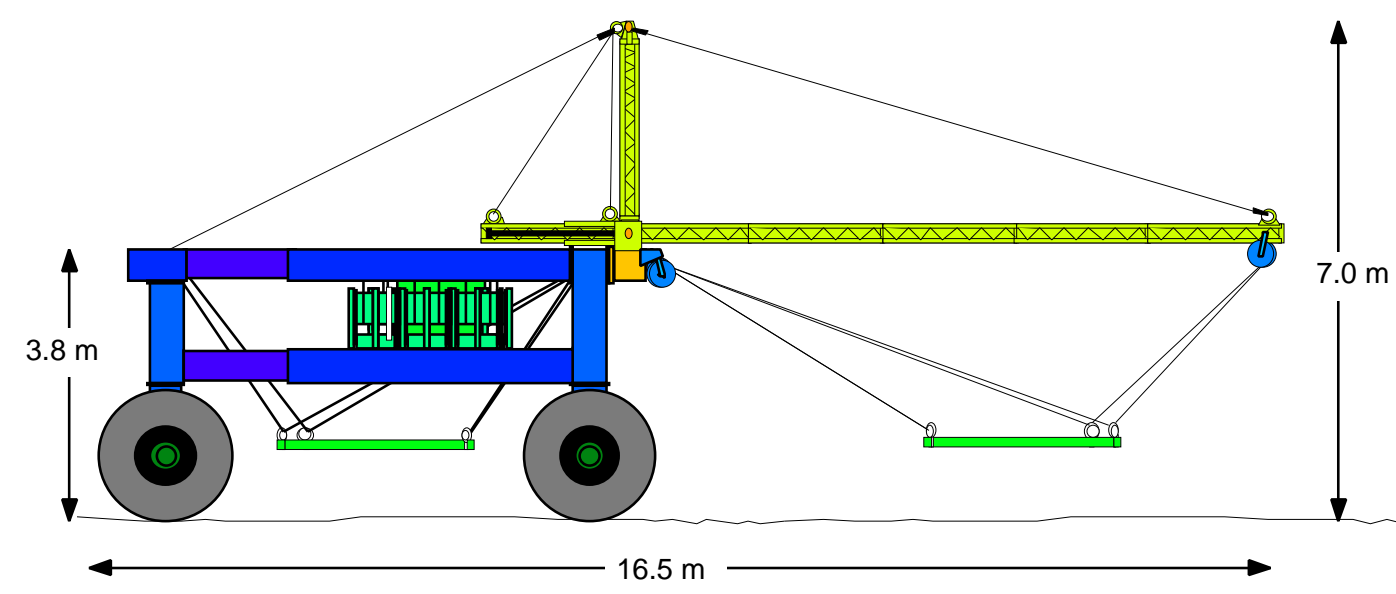

A cantilevered boom pivots horizontally about the ATEC width member center point. Cables from the ATEC - Container Mobilizer winches are rerouted over sheaves at the ATEC - CMH boom tip and ATEC front, top frame corners and from there to a triangular spreader bar. The triangular spreader bar can then be controlled as a Stewart Platform parallel link manipulator. Loads can be maneuvered at full winch speeds $(30 \mathrm{~m} / \mathrm{min}$ (99 ft/min) cable speed). An additional pair of winch cables are used for steering the boom. Steering the boom allows the suspended platform to move about a large area while providing six DOF position control of the load. See Figure 12 for a top view. 
FIGURE 12.

ATEC - Material Handler boom components and work volume
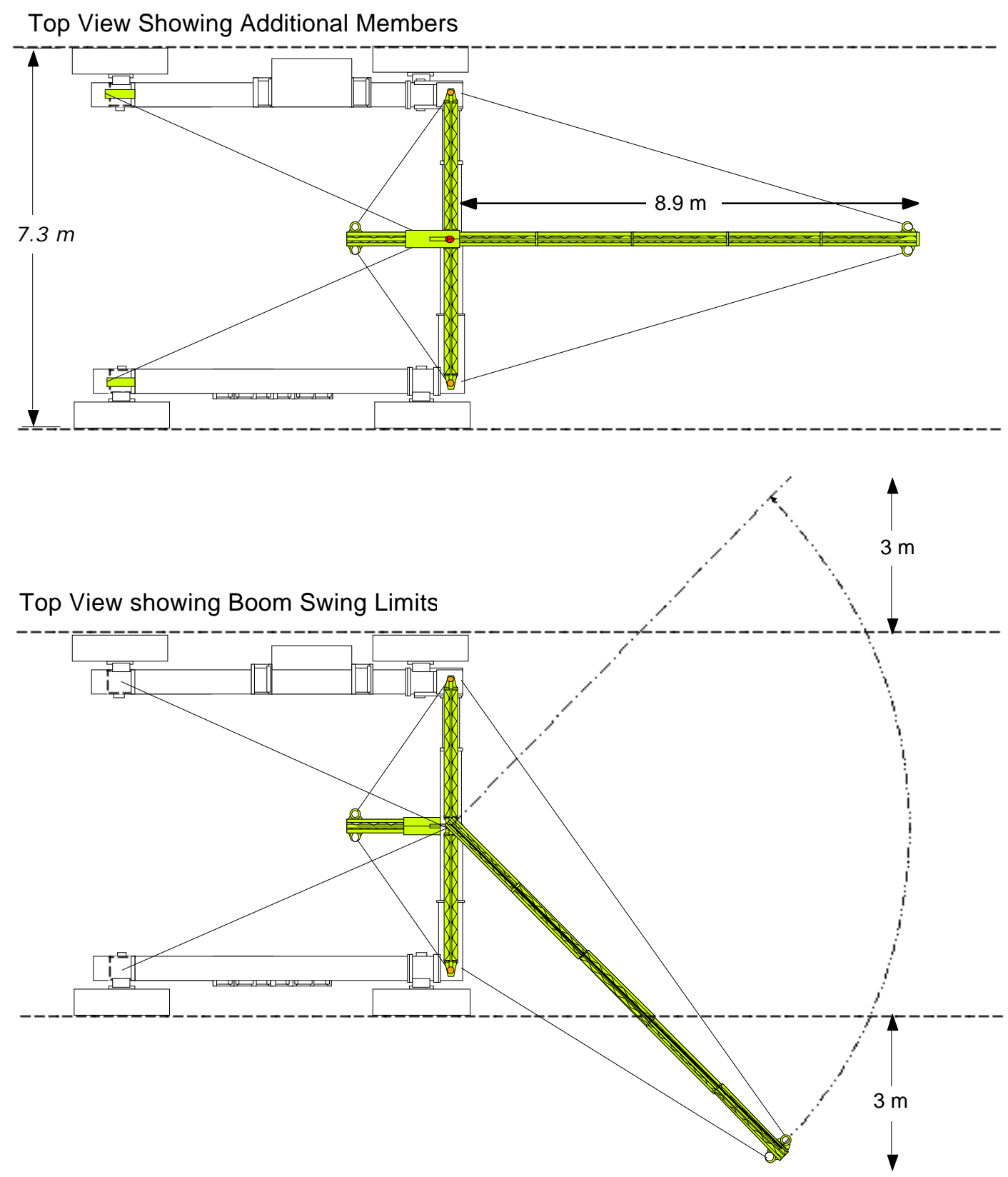

To prevent counterbalance for boom compression into the width telescoping member, a push-rod supported by two truss cables is mounted to the boom rear with truss cable attachment at the width telescoping member ends. To provide boom lift, a vertical stay A-frame is attached to the width telescoping member near the front legs. Fixed length truss cables 
then attach from the A-frame to the boom tip and from the A-frame to the ATEC top, rear members. Also, a lightweight fixed length truss cable is attached from the A-frame to the push rod end to support the rod weight. Therefore, the boom is held in a horizontal plane while sweeping an arc of $\pm 45^{\circ}$, reaching a width of over $12 \mathrm{~m}(40 \mathrm{ft})$, and providing no bending moments in the ATEC width-telescoping member or the legs. A maximum loading of $680 \mathrm{~kg}(1500 \mathrm{lb})$ cantilevered from the boom causes a horizontal force on the A-frame followed by a tension in the rear truss cables. This tension also adds a force to the ATEC rear legs of up to $13,345 \mathrm{~N}$ (3000 lbf) but, the force is negligible due to the structural strength of the ATEC leg frames.

FIGURE 13.

Winches Mounting Location

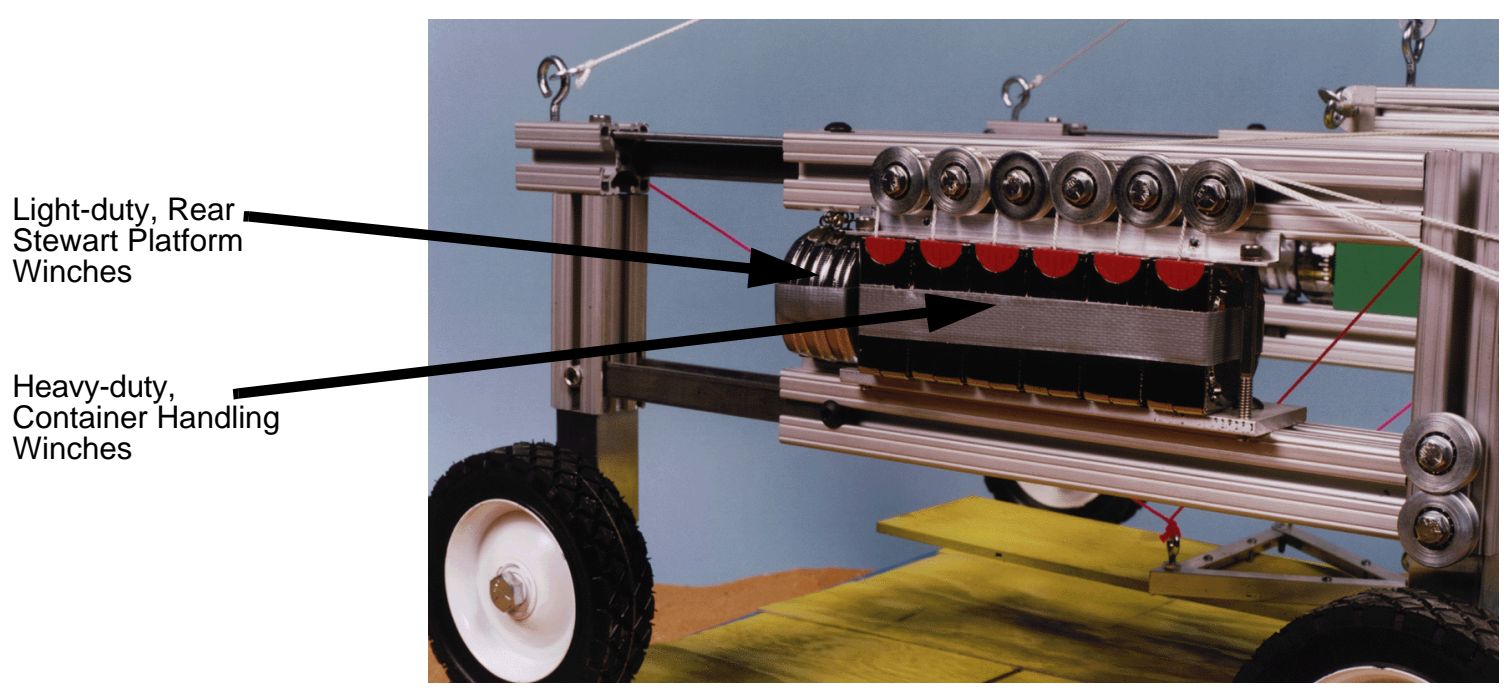

Six additional, lightweight winches are then attached to the ATEC beside the heavy lift winches (see Figure 13). These winches are then routed over the ATEC - Container Mobilizer configured sheaves (only using one sheave from the block and tackles) to form a Stewart Platform configuration upon suspending another triangular spreader bar to these cables. Loads of $680 \mathrm{~kg}(1500 \mathrm{lb})$ can be maneuvered and controlled by the ATEC rear winches for rapid simultaneous construction applications such as airstrip construction.

Control modes for the ATEC - CMH are teleoperation and semi-autonomy. 


\section{Packaging/Deployment Sequence}

ATEC - Cantilevered Material Handler deployment involves a multistep process (see Figures 14 and 15). The following is a description of the deployment procedure shown in the figures. The bracketed numbers show the number of people and the approximate times each step should require. Estimated times are based on an eight person team performing some steps concurrently and others sequentially. If fewer people are available, estimated times will increase.

$\underline{\text { Step } 1}$ - [10 min] Place all A-frame trusses, parts and tools on top of ATEC transfer container and assemble A-frame trusses [4 people]. The ISO container will act as a platform for 4 people to perform the following modifications. Meanwhile, telescope ATEC frame width from $5.4 \mathrm{~m}$ (17

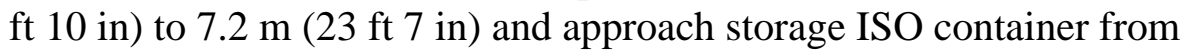
broad side [2 people]. Begin assembly of boom on ground in front of container door [4 people].

$\underline{\text { Step } 2}$ - [10 min.] Secure telescoping member with push-pins [2 person], attach A-frame hinges and pivot pin reinforcement [2 people], and runheavy lift cable from rear winches to A-frame tip [4 people].

$\underline{\text { Step } 3}$ - [5 min.] Lift A-frame into hinge position and drive hinge pins [4 people], place temporary truss post under A-frame tip for support [1 person], attach three fixed length boom support cables to A-frame tip along with a winched boom placement cable [1 person].

$\underline{\text { Step } 4}$ - [5 min.] Hoist A-frame up overhead [4 people] and winch in heavy lift cable until taut [1 person]. Leave A-frame leaning forward $60^{\circ}$ from vertical. Remove support post.

$\underline{\text { Step } 5}$ - [5 min.] Back ATEC away from broad side of container and straddle container from closed end so the assembled boom is in front of crane and directly under leaning A-frame.

$\underline{\text { Step } 6}$ - [15 min.] A) Hoist boom and push-rod assembly (with hinge locked). B) Continue hoisting toward the leaning A-frame apex allowing the boom tip to ride along the ground on it's imbedded wheel [1 person]. C) Once the push rod has cleared the telescoping frame member, raise the angle of the A-frame back toward vertical until the push rod tension cables can be attached from the A-frame hinges to the rear of the pushrod [4 people]. D) Attach the three remaining boom support cables which are dangling from the A-frame apex and winch in the A-frame until it is vertical [ 3 people]. Then lower the boom over the pivot hole in the telescoping frame member and drive the pivot pin into place [2 people]. 
FIGURE 14.

4 - Side View

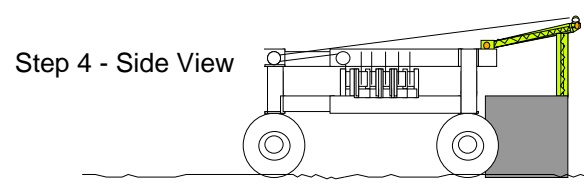

Step 5 - Top View
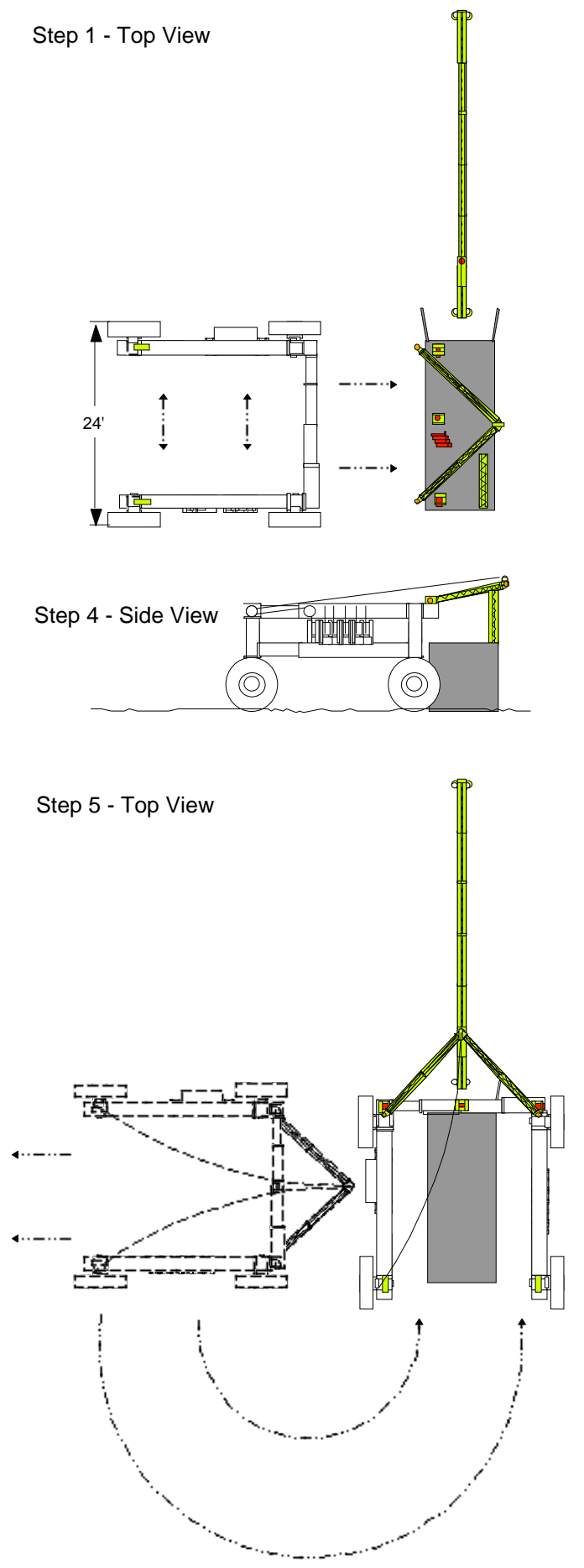
FIGURE 15.

Deployment Sequence for the ATEC - Cantilevered Material Handler (Steps 6 and 7)

A-frame
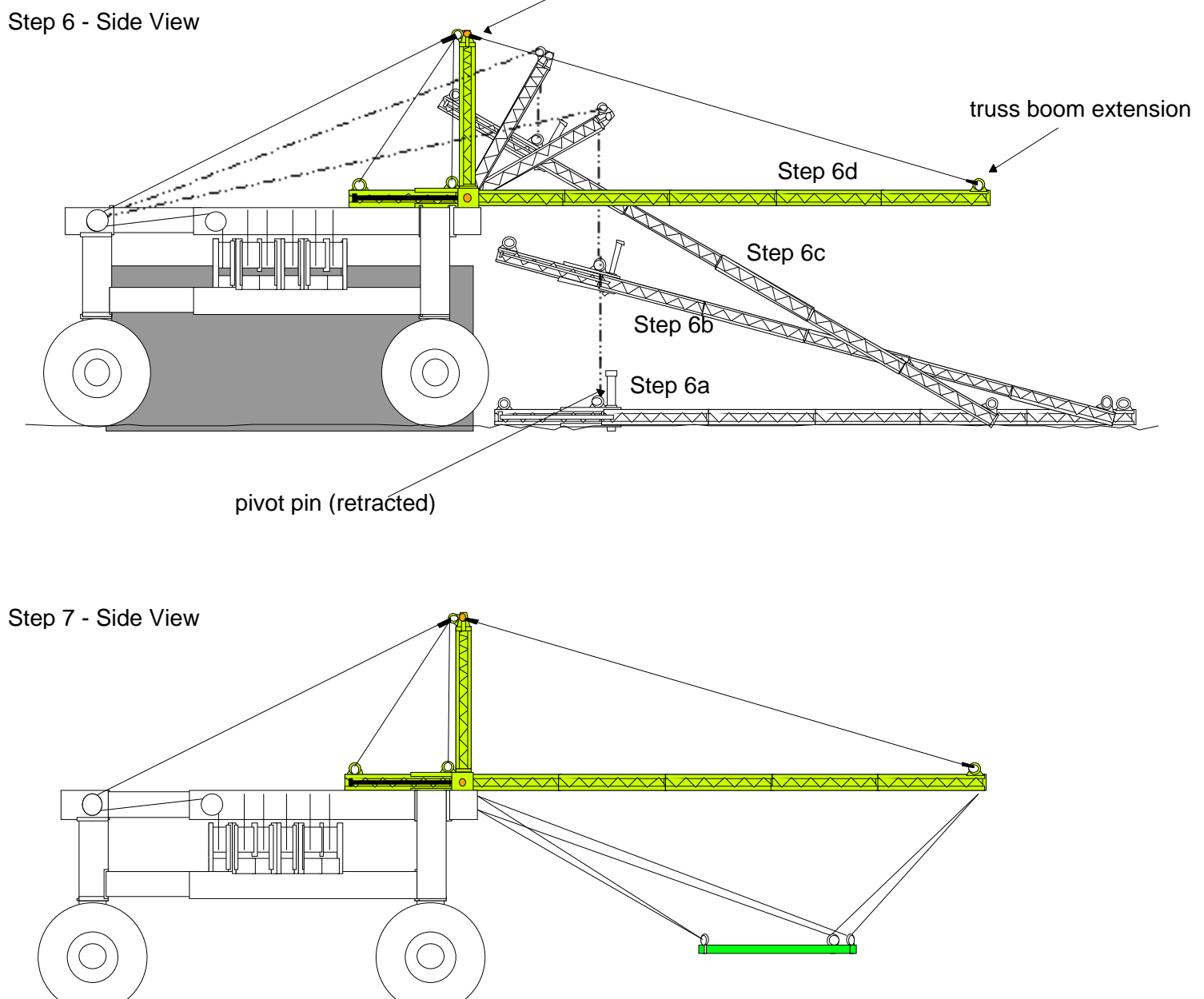
$\underline{\text { Step } 7}$ - [Concurrent with Step 6] Run six light duty cables for cantilevered platform and attach assembled triangular platform [2 people].

Estimated elapsed deployment time $=50 \mathrm{~min}$.

\section{Specifications}

\section{Structure}

Winches

Cabling
The structural members for the ATEC - CMH are an aluminum triangular truss boom, an A-frame truss, and a compression push-rod. The boom is $7.5 \mathrm{~m}(30 \mathrm{ft})$ in length and is attached to the width telescoping member through a pivot joint. The boom end provides a point for two cables of the Stewart Platform to suspend and complete the triangle or to suspend loads from the end point similar to a tower crane. The advantage of this design is to allow the ATEC to be positioned on a stable or finished area while working in front of the crane, such as over ravines and waterways, and for building airstrips.

The A-frame is a structural truss configured to provide nearly pure compression forces on the legs and tension in the width telescoping member while only small bending moments are evident. Truss cables from the boom to the A-frame and A-frame to the crane rear, provide additional forces on these members to counterbalance their weights, boom end loading, and static and dynamic forces that occur during use.

The push-rod provides a pure compression to counterbalance boom loading that can be up to $3765 \mathrm{~kg}$ (8300 Lbs.) while the boom lifts $680 \mathrm{~kg}$ $(1500 \mathrm{lb})$ The push-rod is supported by truss cables that extend from the push-rod end to the width telescoping member ends.

The total weight of all structural members is approximately $356 \mathrm{~kg}$ (785 lb)

Rear ATEC winches are specified as Braden model PD5A-29012-01 winches with the following characteristics: $27 \mathrm{~m} / \mathrm{min}(90 \mathrm{ft} / \mathrm{min})$ first layer wrap speed, $30 \mathrm{~L} / \mathrm{min}$ (8 gal/min) system flow, $680 \mathrm{~kg}(1500 \mathrm{lb})$ line pull, and the system pressure of $10.3 \mathrm{MPa}(1500 \mathrm{psi})$ and a gear ratio of 29:1.

Winch cables measuring $8 \mathrm{~mm}(5 / 16$ in) diameter are $8 \times 25$ Extra Improved Plow Steel (EIPS) with 4.2 t (4.63 tons) nominal strength. Tensions in the push-rod cables experience up to $3402 \mathrm{~kg}(7500 \mathrm{lb})$ and are therefore $15.8 \mathrm{~mm}(5 / 8 \mathrm{in})$ diameter 8 x 25 EIPS cables, with nominal strength of $16.4 \mathrm{t}$ (18.1 tons) providing a 4.8 safety ratio. Rear truss cables experience $18.7 \mathrm{kN}$ (4200 lbf) tension each requiring $12.7 \mathrm{~mm}$ (1/ 
2 in) diameter, 8 x 25 EIPS cables with nominal strength of $103 \mathrm{kN}$ (11.6 ton-f) providing a 5.5 safety ratio. The boom truss cable experiences 37 $\mathrm{kN}$ (8316 lbf) tension requiring two, parallel, $12.7 \mathrm{~mm}$ (1/2 in) diameter, $8 \times 25$ EIPS cables with nominal strength of $103 \mathrm{kN}$ (11.6 ton-f) each (206 $\mathrm{kN}$ total (23.2 ton-f )) providing a 5.6 safety ratio. The total weight of these cables is $54 \mathrm{~kg}(120 \mathrm{lb})$ with end connections.

\section{Airstrip Fabrication}

A main capability of the ATEC - Cantilevered Material Handler (CMH) is airstrip construction. Construction of the airstrip using modular components, such as the 10-A, Inc. Modular Bridging Structure (MBS), is a rapid process whereby components are brought to the site, stacked in last-in, first-out order, which can be rapidly picked and placed by the front and rear Stewart Platforms.

FIGURE 16.

ATEC - Container Mobilizer and Cantilevered Material Handler Assemble Runway

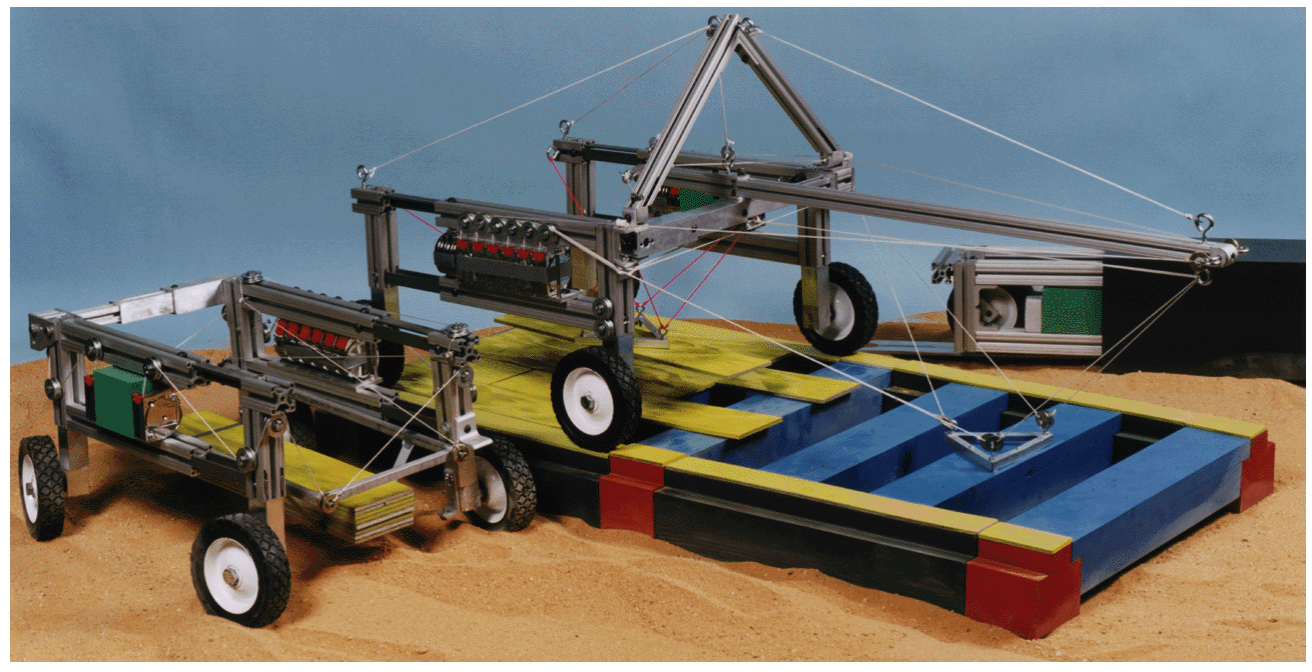


Components can be brought to the site with ATEC - Container Mobilizers or other material handlers, while the ATEC - Cantilevered Material Handlers fabricate the airstrip (see Figure 16).

Figure 17 shows the front spreader bar grabbing a component from the airstrip edge. At this position the ATEC - CMH can reach stacked components and maneuver them into position with 6 DoF. Simultaneously, the rear spreader bar can install deck plates with $6 \mathrm{DoF}$ control.

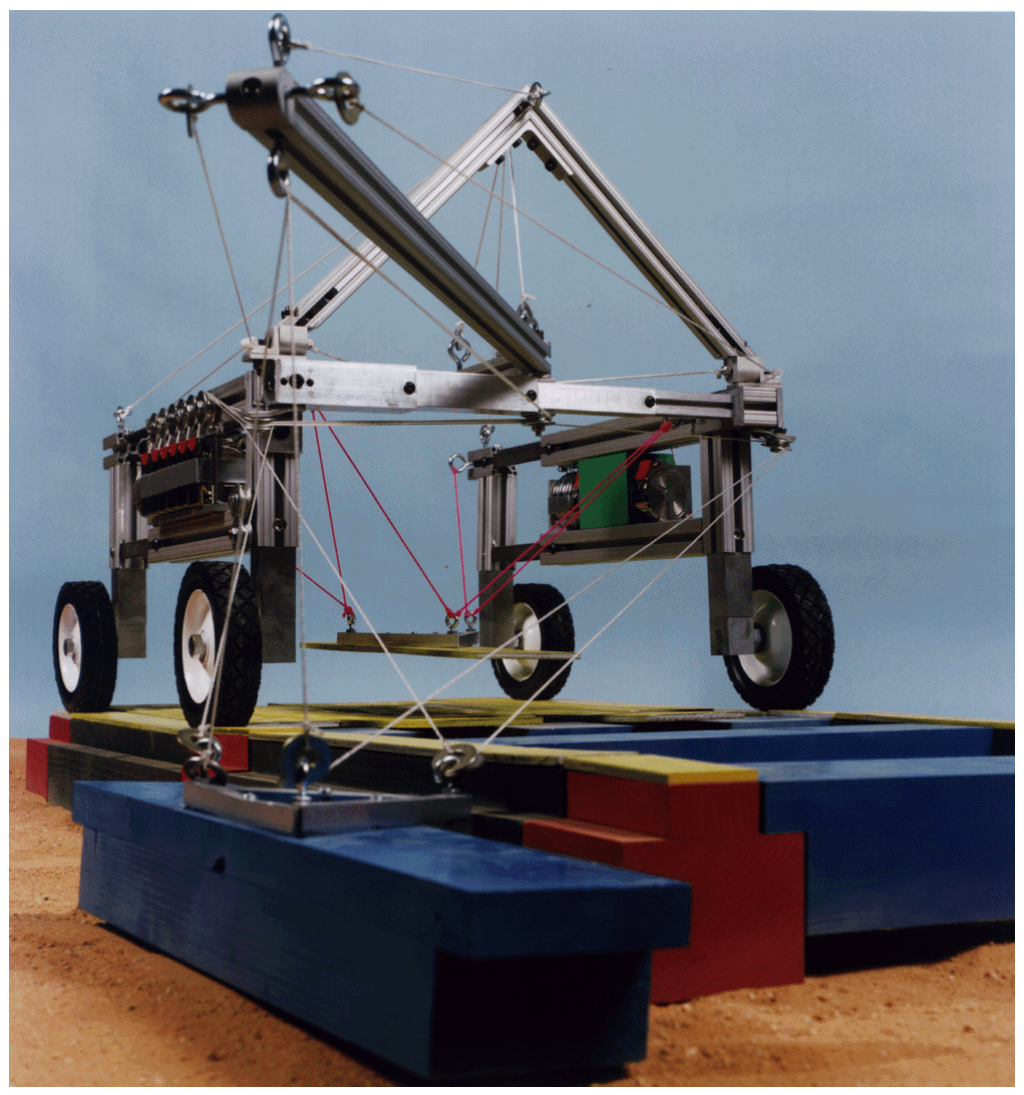

Drills can also be attached to an ATEC to drill at airstrip leg locations to provide anchoring for the legs. Figure 20 shows a model of the drills attached to the ATEC to depict this scenario. 
Airstrip Assembly Assumptions
Although the ATEC can provide functions such as drilling footings, timings were not estimated as part of an airstrip assembly sequence. An assembly procedure was developed to show feasibility and give a rough estimate of the required speed of crane operations. Table 1 shows the worst case component weights.

Worst Case 10A Airstrip Component Weights

\begin{tabular}{|l|c|}
\hline \multicolumn{1}{|c|}{ AIRSTRIP COMPONENT } & MASS (kg) \\
\hline DT & 680 \\
\hline TT & 680 \\
\hline DK - 4 x 20' & 227 \\
\hline DK - 2 x 20' & 113 \\
\hline Column + CCTT + CTT & 680 \\
\hline
\end{tabular}

Using the 10-A ATA component abbreviations (see 10A ATA interim report), these components consist of: Deck Truss (DT), Transverse Truss (TT), Connector Transverse to Transverse (CTT), Connector column to CTT (CCTT), and Connector feet to column (CCL).

A series of assumptions were made:

- Airstrip components will arrive at the site packaged as $6 \mathrm{~m} \mathrm{x} 2.5 \mathrm{~m} \mathrm{x}$ $2.5 \mathrm{~m} \mathrm{(20} \mathrm{ft} \mathrm{x} 8 \mathrm{ft} \times 8 \mathrm{ft})$ ISO pallets. Since packaging criteria will emphasize stacking and volume minimization we can not assume that components are placed optimally for construction purposes. The ATEC will unpack the containers, deliver material to the construction site, pre-assemble components, install the footings, and construct the airstrip superstructure.

- The construction crane can drive and swing the boom while carrying the load.

- It takes at least 5 min to clear the ground and place each footing including anchors.

- At the beginning of the airstrip construction, ATECs are assembled and ready for operation.

- Material can not always be placed inside the construction zone. During construction with no columns or low columns, the material would be in the way, obstructing component placement. 
- DTs, TTs, decks and columns are assumed to be oriented along the airstrip in order to place the component's c.g. closer to the construction site and reduce the required length of the crane boom.

- Columns and CCTTs come pre assembled in the ISO containers

- The ATEC spreader bars are equipped to permit the DTs to be rotated at least $90^{\circ}$ in the horizontal plane and the columns to be rotated at least $90^{\circ}$ in the vertical plane. Columns can be picked up and rotated into a vertical position in order to be installed. DTs can be picked up from the side and rotated into position.

- Pick and place times for different components are assumed to be roughly the same. Each pick/place is estimated as one operation, pick counts as half an operation, place counts as half an operation. Load movement and crane travel times are either negligible or averaged into the pick/place time.

Some off-line assembly is assumed to speed airstrip construction because some of the assembly tasks can be performed in parallel with other tasks. While pre-assembly must be performed, doing it off-line is optional. If we assume off-line assembly we can unpack and repack components and pre-assemble submodules to optimize material delivery to the construction process. The following subassemblies will save significant time if they are done off-line.

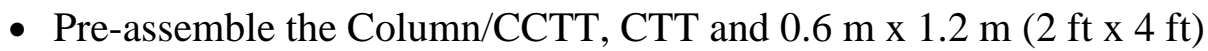
Deck.

- Pre-assemble the TT and the $0.6 \mathrm{~m}$ x $6 \mathrm{~m}$ (2 ft x $20 \mathrm{ft}$ ) Deck.

Off-line construction has several drawbacks, such as: a staging area is required, material must be delivered from the staging area to the construction site over rough terrain, additional equipment and/or personnel will be required. These considerations must be weighed in deciding whether to rely on off-line assembly and delivery to the construction site. If enough cranes are used, it may be possible to avoid these difficulties by delivering airstrip components directly along the airstrip sides and performing the pre-assembly at the construction site.

Assembly Sequence and Timing
The timing sequence specified here is designed to demonstrate construction at the rate of 6 min per $7.3 \mathrm{~m}(24 \mathrm{ft})$ of airstrip length. Any ATA assembly sequence that can be completed in $10 \mathrm{~h}$ or less would clearly require coordinated parallel efforts between all the task definitions above regardless of whether the process uses a Robocrane or any other form of 
automation. Some complexity in coordination of the required effort can not be avoided.

The airstrip is $15.2 \mathrm{~m} \mathrm{x} 274 \mathrm{~m}(50 \mathrm{ft} \times 900 \mathrm{ft})$ and will consist of 40 modules. Modules are $7.3 \mathrm{~m}$ ( $24 \mathrm{ft}$ ) long (including columns) but decks are

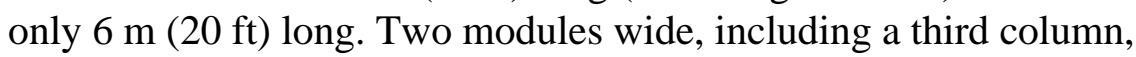
makes up the $15.2 \mathrm{~m}(50 \mathrm{ft})$ width. Therefore, 6 decks must be placed for every 5 modules. The rear crane is dedicated to laying decks and should be able to perform the operation simultaneously.

Two assembly scenarios have been completed.

Scenario 1: One ATEC does the entire assembly. This is not a reasonable option but it is useful for comparison purposes. The sequence for Scenario 1 is as follows:

- ATEC front platform places 2 column/CTTs and 2 TT/DK2x20s

- ATEC front platform places 3 DTs

- ATEC rear platform places 6 DK4x20s, simultaneous to front platform.

- ATEC backs up far enough to move to the other side of the airstrip

- ATEC front platform places 1 column/CTTs and 1 TT/DK2x20

- ATEC front platform places 3 DTs

- ATEC rear platform places $6 \mathrm{DK} 4 \times 20 \mathrm{~s}$, simultaneous to front platform.

The total time to perform this operation is $6.7 \mathrm{~h}$, with $52 \mathrm{~s}$ for each pick, move, and place maneuver.

Scenario 2: Two ATECs do the entire assembly. ATECs A and B are on different sides of the air strip. Crane B is at least one module behind crane A. The sequence for Scenario 2 is as follows:

- 1a front. ATEC A front platform places 2 column/CCTTs and 2 TT/ DK2X20s

- $1 \mathrm{~b}$ front. ATEC B front platform places 1 column/CCTTs and $1 \mathrm{TT} /$ DK2X20s

- 2a front. ATEC A front platform places 3 DTs

- $2 b$ front. ATEC B front platform places 3 DTs

- 1a rear. ATEC A rear platform places 6 DK4x20s, simultaneous to front platform.

- $1 \mathrm{~b}$ rear. ATEC B rear platform places 6 DK4x20s, simultaneous to front platform. 
The total time to perform this operation is $4 \mathrm{~h}$, with $52 \mathrm{~s}$ for each pick, move, and place maneuver.

\section{Utilities}

\section{Spreader Bars}

Spreader bars are necessary for allowing 6 DoF control of the load for a variety of applications. Figure $\mathbf{1 8}$ shows the Triangular Spreader bar configuration made from the Container Mobilizer spreader bar shown in Figure 10. Two spreaders can be made from the Container Mobilizer spreader bar, measuring $2.5 \mathrm{~m}$ ( $8 \mathrm{ft} 4 \mathrm{in}$ ) equilateral, and are used during applications such as: excavating, berming, drilling, sawing, vehicle maintenance, and airstrip construction. The joints of the spreader bar are hinge joints whereby the hinge pins are also eye bolts for cable connections. The Triangular spreader bars weigh approximately $98 \mathrm{~kg}(217 \mathrm{lb})$ each.

\section{FIGURE 18.}

\section{Triangular Spreader Bar}

Top View

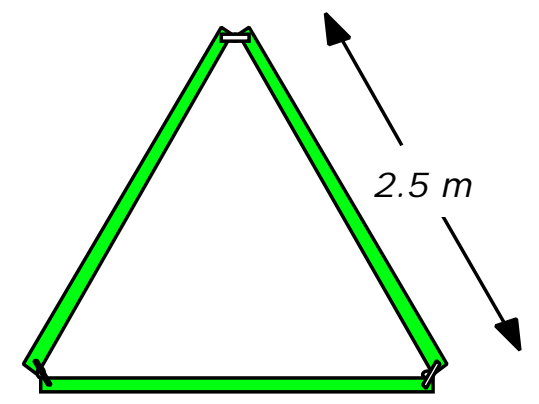

Side View

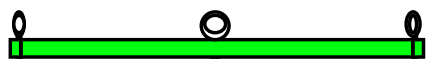

\section{Digging Tools}

Figure 19 shows two types of digging tools that can be used, A) a high speed digging arm, and B) a bull-dozer style blade for scraping. Both concepts are practical. The high speed digging bar is similar to a chain saw typically used to dig trenches rapidly. The same arm could be used to dig trenches, construct berms, or dig footings. Power for the digging arm is available from an ATEC optional hydraulic port. 
By lifting a loaded container and suspending the container from the cables (i.e. not rested on the shelves, a scraping blade can be attached to the spreader for doing excavation, berming, and scraping. This configuration requires no additional power from the ATEC.

\section{FIGURE 19. $\quad$ Earth Moving Optional Tools}
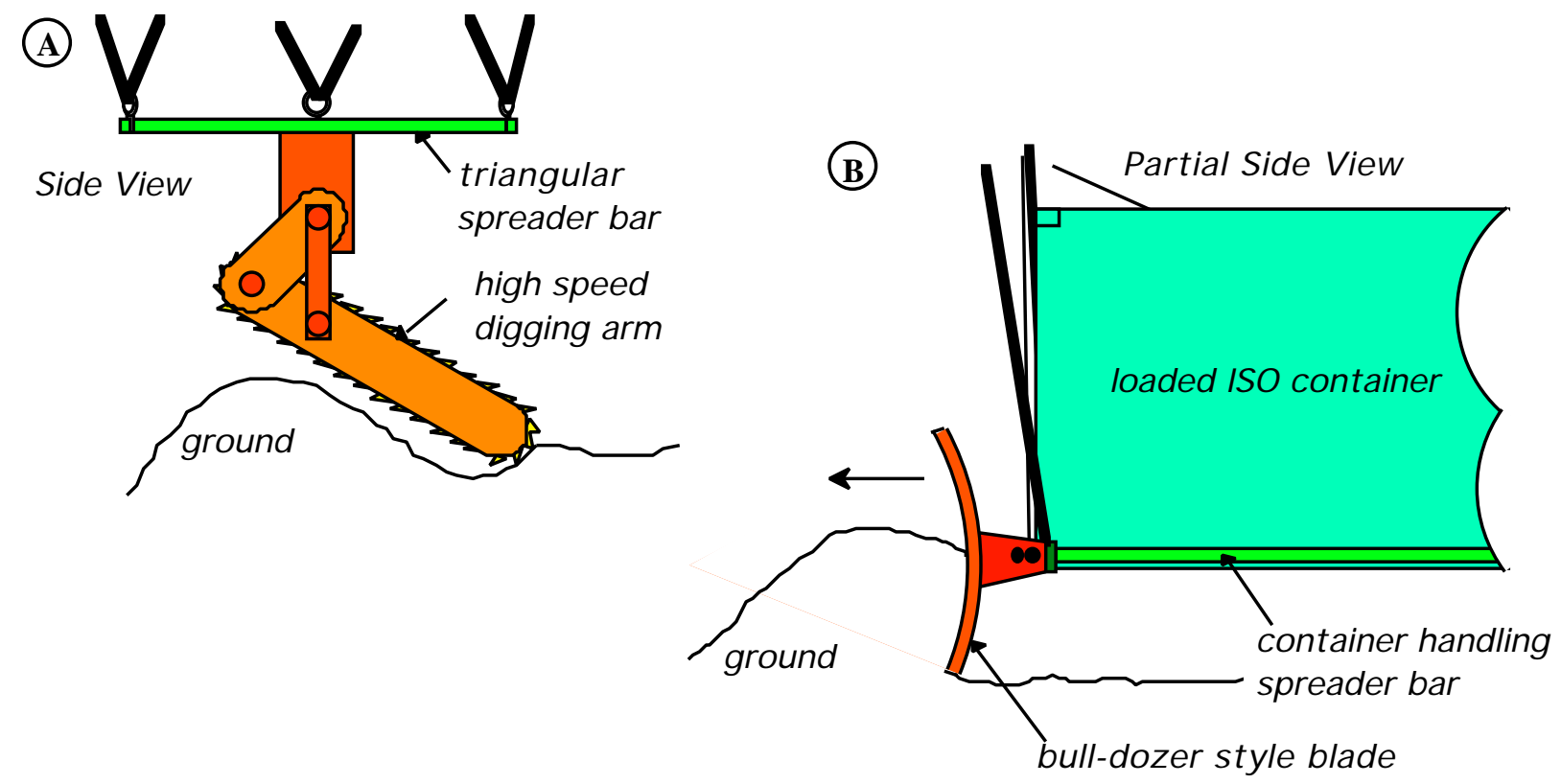

\section{Other Tools}

Other tools such as: drills, saws, and grippers, provide a variety of applications the ATEC can perform. For drilling, high speed drills can be attached to the optional hydraulic power ports and mounted on the container shelves for drilling holes for footings or posts. Figure 20 shows an ATEC model depicting this scenario. 
FIGURE 20.

Scale Model ATEC Drilling Footing Anchor Holes

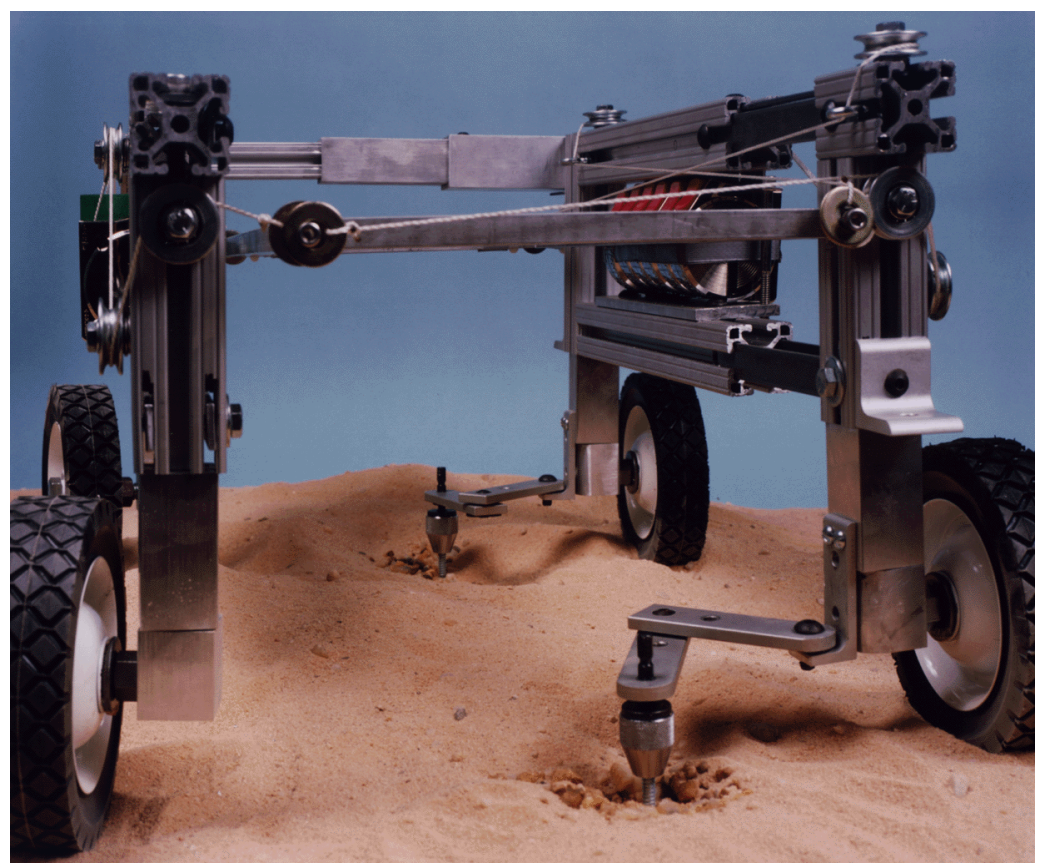

Chain saws can be attached to the triangular spreader bar and powered by ATEC hydraulic power for felling trees or clearing brush and debris.

Grippers can be attached similarly for material handling of break-bulk loads and vehicle maintenance. Loads of up to $23 \mathrm{t}$ ( 25 ton) can be lifted and maneuvered with 6 DOF. Both tools and grippers can be operator controlled using teleoperation with a simple joystick. 


\section{Model Photos}

The following is a series of photographs showing scale models built as a proof of concept for the Phase II ATEC Project:

1. 1/12th Scale model of the packaged ATEC.

2. 1/12th Scale model of the ATEC being deployed. Silver boxes on side represent winches.

3. 1/12th Scale model of the ATEC out of the container and ready to deploy jacks.

4. Top view of the $1 / 12$ th scale model out of the container and ready to deploy jacks.

5. Side view of 1/12th scale model ATEC handling/mobilizing a container.

6. Front/side view of ATEC performing container handling/mobility.

7. 1/12th Scale model ATEC performing side-to-side mobility to align a container with another for placement.

8. Close-up of 1/12th scale model showing spreader bar connection to container and "shelf" type connection of spreader bar to ATEC.

9. Close-up of 1/12th scale model spreader bar connected to container and ready to place on "shelf" type ATEC connection.

10. ATEC 1/12th scale model showing container ready to be stacked on another container.

11. ATEC $1 / 12$ th scale model showing container stacking on another container. Note roller for container edge guidance.

12. ATEC $1 / 12$ th scale model showing container stacking on another container.

13. ATEC 1/12th scale model ready to attach spreader bar to top of container since no access is available to bottom ISO locks.

14. ATEC 1/12th scale model with spreader bar attached to top container ISO locks and ready to lift.

15. ATEC $1 / 12$ th scale model ready to straddle and grab a flat-rack ISO container.

16. ATEC 1/12th scale model performing drilling operation.

17. ATEC-CMH 1/12th scale model showing boom support structure.

18. ATEC-CMH 1/12th scale model maneuvering dual work platforms. 
19. ATEC 1/12th scale model supplies deck plates while ATEC-CMH constructs airstrip.

20. ATEC 1/12th scale models showing relative sizes. Multi-colored runway components show outside dimension sizes only. 
If you would like to see the photos, please e-mail Debra Russell for a hard copy of this paper. Her e-mail address is debra.russell@ nist.gov. 


\section{DETAILED SPECIFICATIONS}

TABLE 2.

\begin{tabular}{|c|c|c|c|}
\hline ITEM & $\begin{array}{c}\text { UNIT } \\
\text { MASS } \\
(\mathbf{k g})\end{array}$ & QTY. & $\begin{array}{l}\text { TOTAL } \\
\text { MASS } \\
\text { (kg) }\end{array}$ \\
\hline \multicolumn{4}{|l|}{$\begin{array}{l}\text { CONTAINER } \\
\text { MOBILIZER }\end{array}$} \\
\hline Gantry & 1566 & 1 & 1566 \\
\hline Engine/housing & 453 & 1 & 453 \\
\hline fuel/hydraulic fluid & 3.6 & 80 & 290 \\
\hline tires & 435 & 4 & 1742 \\
\hline drive systems & 340 & 4 & 1360 \\
\hline steer motors, brakes & 226 & 4 & 907 \\
\hline wheels & 264 & 4 & 1058 \\
\hline wheel joints & 136 & 4 & 544 \\
\hline winches/servo valves & 77 & 8 & 617 \\
\hline cables & 161 & 1 & 161 \\
\hline sheaves & 8 & 40 & 320 \\
\hline hydraulic hose & 327 & 1 & 327 \\
\hline spreader bar & 317 & 1 & 317 \\
\hline controls/computer & 45 & 1 & 45 \\
\hline \multicolumn{4}{|l|}{$\begin{array}{l}\text { CANTILEVERED } \\
\text { MATERIAL HANDLER } \\
\text { ADDITIONS: }\end{array}$} \\
\hline structural components & 431 & 1 & 431 \\
\hline boom steer motor, brake & 226 & 1 & 226 \\
\hline 1t. duty winches, sheaves & 27 & 6 & 163 \\
\hline \multirow[t]{2}{*}{ rear truss cables } & 5 & 1 & 5 \\
\hline & & $\begin{array}{l}\text { TOTAL } \\
\text { ATEC } \\
\text { MASS }\end{array}$ & 10,532 \\
\hline \multirow[t]{2}{*}{ MILVAN Cargo Container } & & & 2163 \\
\hline & & $\begin{array}{c}\text { TOTAL } \\
\text { SHIPPING } \\
\text { MASS }\end{array}$ & 12,696 \\
\hline
\end{tabular}




\section{Weight Analysis}

The ATEC - Container Mobilizer weight can be broken down into components as shown in Table 2. The above table shows the major systemcomponents for both the ATEC - Container Mobilizer and Cantilevered Material Handler with a total weight of $10.5 \mathrm{t}$ (11.6 tons). This weight is inclusive of all materials to be shipped in a single container. Including the MILVAN - General Cargo Container, the shipping weight then totals 12.7 $\mathrm{t}$ (14 tons). Estimates were made for most ATEC components based on the: FY94 weight analysis, research, and calculations using known materials and dimensions. Therefore, the table should be used as an estimate of component weights. With extended research, lighter and more accurate component weights can be included in the ATEC design.

\section{Cost and Fabrication Time}

The cost of a current mobile gantry crane can be approximated at $\$ 173,000$ including the following standard features:

- $6 \mathrm{~m}$ x $6 \mathrm{~m}(20 \mathrm{ft}$ x $20 \mathrm{ft})$ inside clearance area,

- $6 \mathrm{~m}(21 \mathrm{ft})$ wheelbase,

- diesel engine,

- steel structure with approximately $0.4 \mathrm{~m}$ (18 in) box steel beams,

- 4 wheel drive,

- and $45 \mathrm{t}$ (50 ton) capacity.

A standard 23 t (25 ton) capacity mobile gantry crane with the above features can currently be purchased at approximately $\$ 118,000$. NIST estimates, based on these standard cranes, that the $23 \mathrm{t}$ ( 25 ton) capacity ATEC with all features described within this document referring to both the ATEC - Container Mobilizer and Cantilevered Material Handler configurations, will cost approximately $\$ 200,000$ during mass production.

Fabrication time of standard mobile gantry cranes are on the order of one piece within 90 days or 100 pieces fabricated in 13 months. Comparative estimates for the ATEC fabrication time can be assumed since standard inventories will include the ATEC once prototype stages are complete. 


\section{Industry Contacts}

During the course of the ATEC project, we contacted several industrial equipment vendors to research assorted crane designs, components and applications. These contacts provided background in current crane designs and materials used so we could determine the current state of the art in crane design. Also, contacts provided the relative trade-offs between cost and availability of specific crane components that we chose to include in our ATEC design. And finally, some of our contacts were with civilian and military crane/material handling operators in order to determine the capabilities of current material handling equipment and the needs of mobile crane operators.

A list of our contacts follows:

- Shuttlelift ${ }^{\mathrm{TM}}$, Inc.: John Kacmarynski, Ken Davis, and Tom Feider provided mobile gantry crane expertise, pricing and delivery times.

- Robotics Technology, Inc.: Bob Finkelstein and Joe Eisman provided technical expertise in the area of robotics and automated systems.

- 10A Inc.: Yair Tene and Noam Tene provided airstrip component specifications.

- Drehtainer Technik/Forschler and Assoc.: Helmut Meyer/George Forschler presented the Lift-Tainer

- Bridgestone/Firestone Off Road Tire Co.: Jack Dutcher provided tire sizes and weights.

- Titan Wheel Co.: David Cool provided specifications on wheel designs, rims, hubs including pricing and weights.

- Shulmar, Inc.: Ray Saunders provided leasing and site visit information for a mobile gantry crane.

The project team visited U.S. Marine Corps Camp LeJeune in Jacksonville N.C. (June 1995). We toured their facility and inspected the Marine Corps current inventory of cargo handling equipment along with the other partners working under Expeditionary Engineering contracts.

Some of the cargo handling equipment available for demonstrations were the RTCH, TRAM, EBFL, and DTC. These assorted cargo handlers varied greatly in their size and capacity. The largest of the inventory, by far, was the RTCH which can lift, manipulate and mobilize loaded ISO containers as a front-end-loader. The RTCH has the drawback of being heavier (47 $\mathrm{t}$ (52 tons)) than the cargo it is lifting since it relies on a counterweight for balance. It is therefore not helicopter transportable, which is 
an ATEC requirement. The other equipment ranged from extended boom fork lifts, such as the TRAM, which are useful for manipulating empty containers to the EBFL ( $4.5 \mathrm{t}$ (5 tons) capacity) and the DTC which has a $1.8 \mathrm{t}$ ( 2 tons) capacity and fits inside an ISO container. The latter three were all helicopter transportable but for loaded ISO container handling operations, especially in rugged terrain, the RTCH was the only game in town.

We also saw a dolly set lift transportable container mobilizer which is manually attached to each end of a container by 4 marines in less than and hour. This dolly set was interesting because of its minimal design. It utilized the structure of the container and simply jacked the container up off the ground by forcing the wheels from either end of the container up against the container. The model we saw acted solely as a trailer and had no onboard power or active steering. However, the idea of using the rigidity of the container structure was interesting to us and we tried to utilize this concept in our mobilizer design.

The project team also visited the Occaquan River Marina to observe operations of a Travelift $23 \mathrm{t}$ (25 ton) mobile gantry crane as it performed heavy-lift cargo handling tasks. The cargo being manipulated at this marina were, of course, boats. However, we saw the mobile gantry crane traverse unimproved surfaces under heavy loads. We have since based our ATEC design on mobile gantry cranes such as this due to their relatively lightweight structure, simplicity of design, and maneuverability. 


\section{RECOMMENDATIONS}

Based on the information presented in this document, it is our recommendation that the ATEC include the following design features:

\section{$\underline{\text { ATEC - Container Mobilizer: }}$}

- The ATEC will look similar to Figure 1. It will include four independently controlled wheels and eight independently controlled winches acting upon a spreader-bar. It will deploy from one $6 \mathrm{~m}(20 \mathrm{ft})$ ISO Container, weighing $14.5 \mathrm{t}$ (16 tons) or less, deploy in the field, and be controlled via teleoperation or master/robot (walk along) control.

- It's capacity is $22.7 \mathrm{t}$ ( 25 tons) maximum for $6 \mathrm{~m}$ (20 ft) ISO container size loads. Container mobilization, and many other applications can be completed as designed.

- The ATEC will move at a rate of $16 \mathrm{~km} / \mathrm{h}$ (10 mi/h) or more; speed is application dependant.

- Eight or fewer Marine Corps. personnel can erect the crane in approximately $40 \mathrm{~min}$; fewer personnel will require more time.

- Control is intuitive; personnel with limited training will have full crane functionality available.

\section{ATEC - Cantilevered Material Handler}

- Reconfigurability of the ATEC - Container Mobilizer(see Figures 16 and 17) into an ATEC - Cantilevered Material Handler can be completed as designed and deployed in the field.

- It will have a farthest reach (9 m (30 ft)) capacity of $680 \mathrm{~kg}(1500$ Lbs.) and traverse at winch speeds of up to $27 \mathrm{~m} / \mathrm{min}$ (90 ft/min).

- It will have two RoboCranes, one cantilevered, a second within the mobilizer frame. These can be operated simultaneously. A rear spreader bar and the cantilevered spreader bar will have 6 DoF control using teleoperation of each from a joystick.

- Eight Marine Corps. personnel can erect the crane in less than one hour from an ATEC - Container Mobilizer; fewer personnel will require more time.

- Control is intuitive; personnel with limited training will have full crane functionality available. 


\section{FY97 Proposal}

(The following proposal is directly from the FY95 Final ATEC Project Report)

During fiscal year 1997, NIST proposes the following tasks be performed by NIST and other sub-contractors so as to move the ATEC technology to Phase III:

1. Specify and procure or lease a Shuttlelift or comparable mobile gantry crane with $23 \mathrm{t}$ ( 25 ton) capacity and hydraulic power, winches and fourwheel drive systems, all cabling, sheaves and necessary hardware. [2 man-months]

2. Modify the crane control system to allow for coordinated control of all eight winches similar to the Robocrane ${ }^{\circledR}$. [3 man-months]

3. Develop a container handling spreader bar similar to the Phase II design previously described. [2 man-months]

4. Demonstrate: container handling of ISO container size loads over uneven terrain and stacking of ISO containers. [2 man-months]

5. Design, construct and demonstrate a full scale ATEC - Cantilevered Material Handler using the mobile gantry crane base system. [2 manmonths]

6. Procure six additional winches and provide simultaneous coordinated control of front and rear platforms. [4 man-months]

7. Develop alternative concepts for performing expeditionary tasks within the OMFTS arena. [1 man-month]

\section{Total NIST Labor during FY96: \$230k}

Materials for the project will include: leasing a mobile gantry crane with 8 heavy lift winches, and procuring 6 lightweight winches, structural elements, amplifiers, and miscellaneous items.

\section{Approximate Materials Total: \$110k*}

\section{TOTAL}

\section{\$340k}

*with a crane lease totaling $\$ 60 \mathrm{k}$. 


\section{FY98 Proposal **}

Design, fabricate and demonstrate a full scale $23 \mathrm{t}$ (25ton) capacity ATEC prototype. It will demonstrate packaging, deployment, container mobilization, Stewart Platform tool/equipment manipulation and teleoperative control capabilities. Table 3 shows a basic cost outline for the project:

TABLE 3.

FY97 Proposed Cost Outline for a Full-Scale Prototype ATEC

\begin{tabular}{|c|c|c|c|}
\hline MATERIALS & & & \\
\hline ITEM & UNIT COST (\$K) & No. & TOTAL \\
\hline Base Frame, Power, Vehicles & 150 & 1 & 150 \\
\hline Winches, cables, sheaves & 8 & 8 & 64 \\
\hline Winches, cables, sheaves & 6 & 3 & 18 \\
\hline Computer & 15 & 1 & 15 \\
\hline Electronics, Amps, Sensors & 25 & 1 & 25 \\
\hline \multirow[t]{2}{*}{ Miscellaneous } & 10 & 1 & 10 \\
\hline & \multicolumn{2}{|c|}{ Sub-Total: } & $\$ 282 k$ \\
\hline LABOR: & TIME (MM) & & \\
\hline Planning & 2 & & \\
\hline Procurements & 3 & & \\
\hline Design & 6 & & \\
\hline Fabricate & 6 & & \\
\hline Software & 5 & & \\
\hline Electronics/Hydraulics & 6 & & \\
\hline Integration & 3 & & \\
\hline Testing & 4 & & \\
\hline \multirow[t]{2}{*}{ [Labor @ \$175k/year] } & 35 x \$14.6k: & & $\$ 511 k$ \\
\hline & & Total: & $\overline{\text { \$793k }}$ \\
\hline
\end{tabular}




\section{APPENDIX I}

\section{Phase I Report}

The following document is a copy of the Phase I ATEC Final Report.

(Copies of the unpublished Phase I ATEC Final Report are available upon request.) 


\section{APPENDIX II}

- The following are specifications for a mobile gantry crane and winches. These components significantly added to the design concept and are included in this report as additional information. The specifications are as follows:

- Shuttlelift ${ }^{\mathrm{TM}}$ SL50 Specification Sheet

- Shuttlelift ${ }^{\mathrm{TM}}$ SL25 Specification Sheet

- Braden 5.8A Hydraulic Winch Series

(These documents are unpublished and are available upon request from NIST or the vendor.) 